\title{
Benthic oxygen exchange in a live coralline algal bed and an adjacent sandy habitat: an eddy covariance study
}

\author{
Karl M. Attard ${ }^{1,2, *}$, Henrik Stahl ${ }^{3,4}$, Nicholas A. Kamenos ${ }^{5}$, Gavin Turner ${ }^{3}$, \\ Heidi L. Burdett ${ }^{5,6,7}$, Ronnie N. Glud ${ }^{1,2,3,8}$ \\ ${ }^{1}$ Nordic Centre for Earth Evolution (NordCEE), University of Southern Denmark, 5230 Odense M, Denmark \\ ${ }^{2}$ Greenland Climate Research Centre, Greenland Institute of Natural Resources, 3900 Nuuk, Greenland \\ ${ }^{3}$ Scottish Association for Marine Science, Scottish Marine Institute, Oban PA37 1QA, UK \\ ${ }^{4}$ Natural Science and Public Health Department, Zayed University, PO Box 19282, Dubai, United Arab Emirates \\ ${ }^{5}$ School of Geographical and Earth Sciences, University of Glasgow, Glasgow G12 8QQ, UK \\ ${ }^{6}$ Department of Earth and Environmental Sciences, University of St. Andrews, St. Andrews KY16 9AL, UK \\ ${ }^{7}$ Scottish Oceans Institute, University of St Andrews, St. Andrews KY16 8LB, UK \\ ${ }^{8}$ Arctic Research Centre, University of Århus, 8000 Århus C, Denmark
}

\begin{abstract}
Coralline algal (maerl) beds are widespread, slow-growing, structurally complex perennial habitats that support high biodiversity, yet are significantly understudied compared to seagrass beds or kelp forests. We present the first eddy covariance (EC) study on a live maerl bed, assessing the community benthic gross primary productivity (GPP), respiration $(R)$, and net ecosystem metabolism (NEM) derived from diel EC time series collected during 5 seasonal measurement campaigns in temperate Loch Sween, Scotland. Measurements were also carried out at an adjacent ( 20 m distant) permeable sandy habitat. The $\mathrm{O}_{2}$ exchange rate was highly dynamic, driven by light availability and the ambient tidally-driven flow velocity. Linear relationships between the EC $\mathrm{O}_{2}$ fluxes and available light indicate that the benthic phototrophic communities were lightlimited. Compensation irradiance $\left(E_{\mathrm{c}}\right)$ varied seasonally and was typically $\sim 1$.8-fold lower at the maerl bed compared to the sand. Substantial GPP was evident at both sites; however, the maerl bed and the sand habitat were net heterotrophic during each sampling campaign. Additional inputs of $\sim 4$ and $\sim 7 \mathrm{~mol} \mathrm{~m}^{-2} \mathrm{yr}^{-1}$ of carbon at the maerl bed and sand site, respectively, were required to sustain the benthic $\mathrm{O}_{2}$ demand. Thus, the 2 benthic habitats efficiently entrap organic carbon and are sinks of organic material in the coastal zone. Parallel deployment of $0.1 \mathrm{~m}^{2}$ benthic chambers during nighttime revealed $\mathrm{O}_{2}$ uptake rates that varied by up to $\sim 8$-fold between replicate chambers (from -0.4 to $-3.0 \mathrm{mmol} \mathrm{O}_{2} \mathrm{~m}^{-2} \mathrm{~h}^{-1} ; \mathrm{n}=4$ ). However, despite extensive $\mathrm{O}_{2}$ flux variability on meter horizontal scales, mean rates of $\mathrm{O}_{2}$ uptake as resolved in parallel by chambers and EC were typically within $20 \%$ of one another.
\end{abstract}

KEY WORDS: Benthic oxygen exchange $\cdot$ Benthic primary production $\cdot$ Coastal carbon cycling Coralline algae $\cdot$ Permeable sediment $\cdot$ Eddy covariance $\cdot$ Benthic chambers

\section{INTRODUCTION}

Maerl beds are composed of dense aggregations of free-living red coralline algae (Rhodophyta, Corralinales) that accumulate on seabed surfaces with low sediment deposition rates and sufficient light avail-

\footnotetext{
${ }^{*}$ Corresponding author: karl.attard@biology.sdu.dk
}

ability (Martin et al. 2014). Maerl beds are slowgrowing, structurally and functionally complex perennial habitats that support a rich diversity of micro- and macroalgae as well as benthic macrofauna (Barbera et al. 2003, Grall et al. 2006), and are important nursery areas for juvenile invertebrates

() The authors 2015. Open Access under Creative Commons by Attribution Licence. Use, distribution and reproduction are unrestricted. Authors and original publication must be credited. 
and fish (Kamenos et al. 2004a,b). Maerl beds occur worldwide and are among the most widespread benthic phototrophic ecosystems in terms of areal coverage (Foster 2001). While their importance for regional biodiversity is increasingly recognized, maerl beds remain significantly understudied compared to other conspicuous benthic ecosystems such as seagrass beds, kelp forests, or shallow-water coral reefs. Coralline algal community productivity and its role in coastal carbon (C) cycling in particular have received little attention. This is surprising considering that the few existing studies on the topic indicate that maerl beds are among the most productive benthic ecosystems, with areal rates comparable to those of seagrass beds (Martin et al. 2005, 2007). Given their role in ecosystem service provision, a better understanding of maerl beds and their role in coastal $\mathrm{C}$ cycling is required.

The most widely used method for estimating benthic primary productivity and $\mathrm{C}$ turnover at the seabed is the benthic $\mathrm{O}_{2}$ exchange rate (Glud 2008). Community rates of benthic gross primary productivity (GPP), respiration $(R)$, and net ecosystem metabolism (NEM) have traditionally been estimated using benthic chamber incubations that quantify areal $\mathrm{O}_{2}$ exchange rates. Typically, chamber incubations enclose a sediment area of $0.1 \mathrm{~m}^{2}$ or less and incubations last only for a few hours. Community based diel assessments of activity therefore assume that the integrated spatial and temporal scales of the chamber incubations are representative of the whole benthic community. Application of benthic chambers in maerl beds is further complicated by the presence of the maerl structure and other large benthic macroalgae and fauna, and the enclosure process excludes the natural variations in hydrodynamics that the organisms otherwise experience. More recently, the aquatic $\mathrm{O}_{2}$ eddy covariance (EC) method (Berg et al. 2003) was introduced, which allows benthic $\mathrm{O}_{2}$ exchange rates to be estimated non-invasively over large $\left(\sim 10\right.$ to $\left.100 \mathrm{~m}^{2}\right)$ areas of the seabed. The EC method combines high-frequency measurements of vertical flow velocity and $\mathrm{O}_{2}$ concentration taken at a single point (typically 10 to $30 \mathrm{~cm}$ above the seabed surface) to estimate the vertical turbulent exchange of $\mathrm{O}_{2}$ within the benthic boundary layer. Under ideal conditions this exchange rate can be considered equal to the depth-integrated areal average sediment $\mathrm{O}_{2}$ dynamics. Since EC measurements are carried out away from the seabed surface, this method is not confined to soft sediments. Importantly, EC measurements provide continuous time series of $\mathrm{O}_{2}$ exchange rates covering one or more days, to help elucidate the dynamics of benthic $\mathrm{O}_{2}$ exchange under changing environmental conditions. This method has been applied to complex coastal benthic habitats such as high-latitude rocky benthic surfaces (Glud et al. 2010), seagrass beds (Hume et al. 2011), and coral reefs (Long et al. 2013, Rovelli et al. 2015), and therefore provides a new valuable tool for estimating the benthic $\mathrm{O}_{2}$ exchange rate of maerl bed communities.

The main objective of this study was to investigate the biogeochemical functioning of a live maerl bed community and an adjacent sandy habitat, and their importance for coastal C cycling. This comparison was conducted by quantifying rates of benthic primary productivity and $\mathrm{C}$ degradation at both sites using the state-of-the-art $\mathrm{EC}_{2}$ flux method during 5 measurement campaigns across all 4 seasons. In addition, benthic chambers were deployed in parallel with the EC to resolve the benthic $\mathrm{O}_{2}$ exchange rate using 2 independent methods.

\section{MATERIALS AND METHODS}

\section{Study site}

The study site was located in the tidal narrows of Caol Scotnish, a sheltered $\sim 0.5 \mathrm{~km}^{2}$ side-loch within the Loch Sween Marine Protected Area on the west coast of Scotland $\left(56^{\circ} 01.99^{\prime} \mathrm{N}, 05^{\circ} 36.13^{\prime} \mathrm{W}\right.$; Fig. 1A).The shoreline rapidly descended to a depth of $\sim 5 \mathrm{~m}$ at mean low water, and this depth remained consistent across the narrows. Closest to the shoreline, the seabed was characterised by bare sediments composed primarily of a mixture of sands, gravels, and relict shell fragments (Fig. 1B). The dominant macrofauna comprised the deposit-feeding black brittle star Ophiocomina nigra, occurring in densities of $\sim 100$ ind $\mathrm{m}^{-2}$. The permeability of the top $\sim 10 \mathrm{~cm}$ of sediments measured on intact cores described by Klute \& Dirksen (1986) was $1.7 \times 10^{-11} \pm 0.2 \mathrm{~m}^{-2}$ (mean $\pm \mathrm{SD}, \mathrm{n}=4$ ). Further out, in the middle of the narrows, the seabed was dominated by a live maerl bed of $\sim 500 \mathrm{~m}$ length and $\sim 40 \mathrm{~m}$ in width, characterised by a dense population of live maerl thalli, Lithothamnion glaciale, and high densities $\left(\sim 1000\right.$ ind. $\left.\mathrm{m}^{-2}\right)$ of the suspension-feeding common brittle star Ophiothrix fragilis and lower densities of the deposit-feeder O. nigra (Fig. 1C). The top 5 to $10 \mathrm{~cm}$ of the maerl bed consisted of a branched structure of live maerl thalli. This layer was underlain by a mixture of relict maerl skeletons and fine sediments that accumulated due to entrapment of finer particles 
by the maerl structures. The combined permeability of the maerl thalli and underlying $\sim 10 \mathrm{~cm}$ of sediments measured on intact cores as described by Klute \& Dirksen (1986) was $2.2 \times 10^{-12} \pm 0.3 \mathrm{~m}^{-2}$ (mean $\pm \mathrm{SD}, \mathrm{n}=4$ ). The flow regime in Loch Sween is tidally-driven, with velocity magnitudes most often within the range of 5 to $10 \mathrm{~cm} \mathrm{~s}^{-1}$. However, short $(\sim 2 \mathrm{~h})$ periods of intensified flow reaching 15 to $20 \mathrm{~cm}$ $\mathrm{s}^{-1}$ coincide with the incoming (flood) tide. The 2 measurement sites were located within $\sim 20 \mathrm{~m}$ of one another. Surface waves were negligible $(<10 \mathrm{~cm})$ during the measurement campaigns.
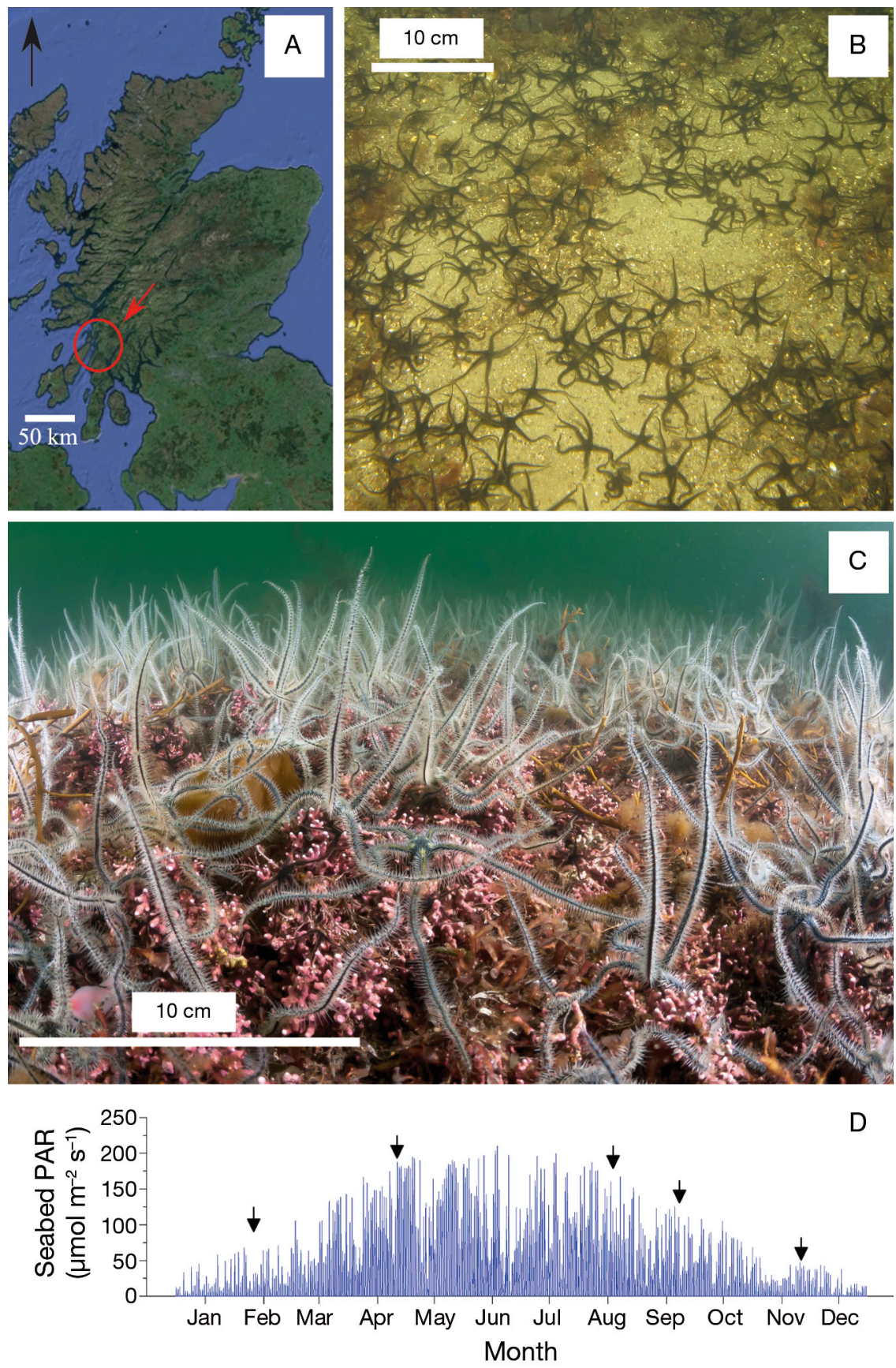

Fig. 1. (A) General location of the 2 study sites investigated in Loch Sween (red arrow) on the west coast of Scotland (map edited from Google Earth). (B) The sand/gravel site with high densities ( 100 ind. $\left.\mathrm{m}^{-2}\right)$ of the deposit-feeding brittle star Ophiocomina nigra, and (C) the live maerl bed with soft brown macroalgae and high densities of the suspension-feeding brittle star Ophiothrix fragilis ( 1000 ind. $\left.\mathrm{m}^{-2}\right)$. Maerl bed image courtesy of Rob Cook (Heriot-Watt University). (D) The 5 measurement campaigns were carried out in different seasons representing contrasting light regimes (black arrows) in Loch Sween 


\section{In situ instrumentation}

\section{Eddy covariance measurements}

For each of the 5 measurement campaigns at Loch Sween, we aimed to obtain EC time series of at least one complete $24 \mathrm{~h}$ period at each of the 2 sites. During the September 2010 and April 2012 campaigns, 2 EC systems were available. This allowed for simultaneous measurements of $\mathrm{EC} \mathrm{O}_{2}$ exchange rates at the 2 sites. During the other campaigns (November 2011, February 2012, August 2012) a single EC system was alternated between the 2 sites. In all cases, EC deployment was conducted by divers who used lift bags to carefully position the EC systems on the seabed. In total, 14 successful EC deployments were made at Loch Sween during the 5 measurement campaigns that altogether integrated $>300 \mathrm{~h}$ of measuring time divided between the 2 sampling sites.

The configuration of the applied EC systems was similar to the original design described by Berg \& Huettel (2008). The main components of the EC systems consisted of an acoustic Doppler velocimeter (ADV; Vector, Nortek) and a Clark-type $\mathrm{O}_{2}$ microsensor with a 10 to $20 \mu \mathrm{m}$ tip diameter (Revsbech 1989). Each microsensor was individually tested for its quality prior to deployment to ensure that it had a $90 \%$ response time of $\leq 0.5 \mathrm{~s}$ and a stirring sensitivity of $<0.5 \%$ (Gundersen et al. 1998). The $\mathrm{O}_{2}$ microsensor signal was relayed to the ADV via a submersible amplifier (McGinnis et al. 2011). The ADV recorded the longitudinal $(u)$, traverse $(v)$, and vertical $(w)$ velocity components as well as the $\mathrm{O}_{2}$ microsensor output in continuous mode at frequencies of 32 or 64 $\mathrm{Hz}$, and in addition collected ancillary information such as instrument pitch and roll, flow direction, and signal strength. The equipment was mounted onto a stainless-steel tripod frame measuring $130 \times 90 \mathrm{~cm}$, designed to minimize hydrodynamic interference. The ADV sampling volume was located $\sim 15 \mathrm{~cm}$ above the seabed surface. Visual inspection by divers ensured that the $\mathrm{O}_{2}$ sensor tips and the ADV measurement volume stood well clear of bottom features such as stones, maerl branches, and benthic macrofauna. The $\mathrm{O}_{2}$ microsensor tip was carefully positioned just at the edge of the ADV sampling volume $\left(0.5 \mathrm{~cm}\right.$ separation) to extract the $\mathrm{O}_{2}$ data close to the ADV measurement point without compromising the velocity measurements. Prior to deployment, the EC $\mathrm{O}_{2}$ microsensors were left to polarize for $\sim 12 \mathrm{~h}$ to minimize sensor drift during deployments. Following polarization, the signal range and response time of each $\mathrm{O}_{2}$ microsensor used was evaluated using water samples of known $\mathrm{O}_{2}$ concentration. A sodium dithionite solution was used for the zero $\mathrm{O}_{2}$ saturation value, and collected bottom water samples were used for the in situ $\mathrm{O}_{2}$ concentration. The $\mathrm{O}_{2}$ concentrations were determined in the laboratory by Winkler titration.

\section{Benthic chamber measurements}

The square-shaped benthic chambers were constructed from semi-transparent Perspex and polyvinyl chloride, and enclosed an area of $961 \mathrm{~cm}^{2}$ $\left(0.1 \mathrm{~m}^{2}\right)$. Each chamber had a removable lid that was fitted with a central rotating cross-shaped stirrer on the underside (Glud et al. 1996). The stirrer was powered by a small, self-contained batterypowered motor and was set to rotate at a constant frequency of $12 \mathrm{rpm}$. This rotation frequency was selected based on prior work by Glud et al. (1996) that characterised the pressure gradients within this type of chamber under controlled conditions. Several chambers were deployed by divers during the night, approximately $1 \mathrm{~m}$ apart from one another during periods that coincided with the EC deployments. A total of 4 chambers were deployed at each site in September, February and April; 3 were deployed in November, and 5 in August. The chambers were gently pushed $\sim 15 \mathrm{~cm}$ into the sediment and the chamber lid was sealed to prevent exchange with the ambient bottom water. A sampling port on the side of the chamber wall allowed water samples from inside the chambers to be retrieved during incubation. A $100 \mathrm{ml}$ water sample was retrieved by the divers at the start and at the end of each of the 3 to $6 \mathrm{~h}$ long incubations using a gas-tight syringe. Once extracted, water samples were transported to shore where they were fixed, stored in the dark and later analyzed in triplicate for $\mathrm{O}_{2}$ concentration by Winkler titration. The decline in $\mathrm{O}_{2}$ saturation between the start and the end of the incubation was $<25 \%$. The benthic chamber walls substantially attenuated the ambient light levels and were therefore not applied during daytime.

A substantial biomass of macroalgae had accumulated on the seabed surface in April. During this campaign, the divers were required to clear small areas of the seabed surface of the largest bits of algae prior to installing the benthic chambers in order to ensure a good seal between the chamber walls and the sediment. The results from this campaign are presented but are not discussed in detail since the flux measurements were likely compromised by this process. 


\section{In situ background environmental parameters}

A conductivity temperature depth (CTD) sensor (XR-420, RBR) equipped with an $\mathrm{O}_{2}$ optode (3830, Aanderaa) and a scalar photosynthetically active radiation (PAR) sensor (QSP-2200, Biospherical Instruments) was mounted onto a separate small stainless-steel frame that held the sensors 15 to 20 $\mathrm{cm}$ above the seabed. The system was deployed by divers at the interface between the maerl and sand sites, approximately equidistant between the 2 measurement sites. The CTD was programmed to record the environmental parameters covering the benthic chamber and EC deployments at $30 \mathrm{~s}$ intervals.

\section{Eddy covariance fluxes}

The $\mathrm{EC} \mathrm{O}_{2}$ fluxes were first extracted from the raw EC dataset and then evaluated for their 'quality' based on a set of defined criteria as detailed in Attard et al. (2014). Flux extraction was carried out using the open source software package Sulfide Oxygen Heat Flux Eddy Analysis (SOHFEA) version 2.0 (www. dfmcginnis.com/SOHFEA). Additional data treatments that are detailed below, but not available in SOHFEA, were carried out in MATLAB ${ }^{\circledR}$ (MathWorks). The datasets were processed for flux extraction in the following order: (1) weak signals in the raw 32 or $64 \mathrm{~Hz}$ ADV velocity data were identified by a low beam correlation and/or low signal strength. Individual data points with beam correlations below $50 \%$ and signal-to-noise ratios below $12 \mathrm{~dB}$ were discarded. (2) The 32 or $64 \mathrm{~Hz}$ raw EC data was averaged down to $8 \mathrm{~Hz}$. This reduced the noise level, and the smaller file size allowed for easier data handling. (3) A spectral analysis was carried out on the $8 \mathrm{~Hz}$ vertical velocity (i.e. $w$ ) and the $\mathrm{O}_{2}$ microsensor data $(C)$. The spectra showed the presence of an inertial subrange, identified as the region on the pressure spectral density plot for $w$ and $C$ where the slope of energy cascade from large scales to the smaller scales followed the predicted $-5 / 3 \mathrm{fit}$, suggesting well-developed turbulence. The spectra were furthermore used to infer that the data reduction through adjacent averaging from 64 or $32 \mathrm{~Hz}$ to $8 \mathrm{~Hz}$ did not result in a loss of signal at high frequency, since most of the turbulent contributions typically occurred at a frequency of $1 \mathrm{~Hz}$ or lower (Fig. 2). (4) The $\mathrm{O}_{2}$ microsensor output was calibrated to the CTD $\mathrm{O}_{2}$ optode data using a linear regression. (5) Spike noise in the $w$ and $C$ data were removed using the

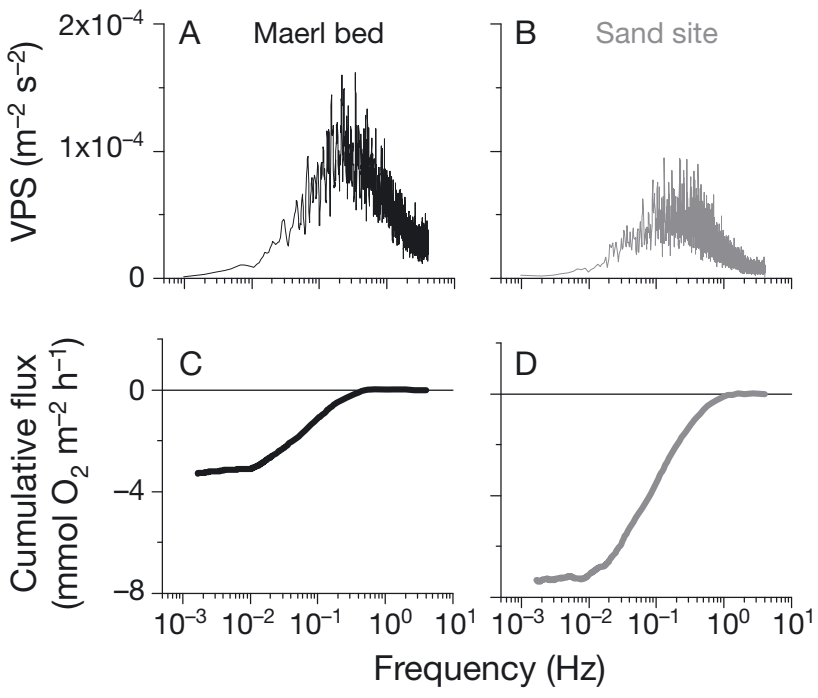

Fig. 2. Variance-preserving Power Spectra (VPS) of the vertical flow velocity for (A) the maerl bed and (B) the sand site. The data used in this example cover a $3 \mathrm{~h}$ dark period when 2 eddy covariance (EC) instruments were measuring in parallel at both sites. The mean $( \pm \mathrm{SE})$ flow velocity magnitude $(U)$ during this period was $6.9 \pm 0.5 \mathrm{~cm} \mathrm{~s}^{-1}$ at the maerl bed and $8.5 \pm 0.5 \mathrm{~cm} \mathrm{~s}^{-1}$ at the sand site. The average cumulative co-spectra (ogives) of the $\mathrm{EC} \mathrm{O}_{2}$ flux for the same period are presented in (C) and (D). The ogives indicate a dominance of flux-contributing eddies within the frequency range of $10^{\circ}$ to $10^{-2} \mathrm{~Hz}$, or 1 to $100 \mathrm{~s}$. The flux is seen to converge at lower frequencies

'3D phase space' method, and the excluded data points were interpolated using a cubic polynomial function (Mori et al. 2007). (6) Coordinate rotation was applied to the global $8 \mathrm{~Hz}$ ADV velocity dataset using the 'planar fit' method to transform measured velocities into streamline coordinates (Lorke et al. 2013). (7) The $\mathrm{O}_{2}$ fluxes (in $\mathrm{mmol} \mathrm{m}^{-2} \mathrm{~h}^{-1}$ ) were extracted from the ADV $w$ and $C$ data as the covariance $\left\langle w^{\prime} C^{\prime}\right\rangle$, where $w^{\prime}$ and $C^{\prime}$ are deviations from a least-squares linear trend fitted to the measured vertical velocity and $\mathrm{O}_{2}$ concentration respectively, and the angle bracket denotes time averaging. Following Reynolds decomposition theory, the vertical velocity vector may therefore be expressed as $w=\langle w\rangle+w^{\prime}$ and the scalar quantity $C=\langle C\rangle+C^{\prime}$ (Berg et al. 2003). The selected time averaging interval is a tradeoff between including as many of the fluxcontributing turbulent eddies as possible while excluding low-frequency non-turbulent contributions such as advective flows (McGinnis et al. 2008, Lorke et al. 2013). To determine the optimal time interval, an analysis was carried out to investigate the effects of averaging time on the mean covariance and subsequent flux estimates for the friction velocity $\left(u_{*}\right)$ and the $\mathrm{O}_{2}$ fluxes. The $u_{*}$ is directly related to the turbu- 
lence regime within the benthic boundary layer (BBL). Estimates for $u *$ were computed from complex Reynolds stress measurements derived from the ADV velocity time series (McPhee 2008). The $u, v$, and $w$ velocity components were decomposed into a mean and deviatory velocity as $u=\langle u\rangle+u^{\prime}, v=\langle v\rangle+v^{\prime}$ and $w=\langle w\rangle+w^{\prime}$. The $u_{*}$ was then calculated as $u_{*}=$ $\left(\left\langle u^{\prime} w^{\prime}\right\rangle^{2}+\left\langle v^{\prime} w^{\prime}\right\rangle^{2}\right)^{1 / 4}$. The mean $u_{*}$ and $\mathrm{O}_{2}$ flux were computed as a function of the ensemble average. A time window of 10 min was consistently identified as the optimal interval for flux calculation at the 2 sites (Fig. 2) . (8) A time-shift correction was applied to the data. Time shifting was performed for each ensemble interval by shifting the $\mathrm{O}_{2}$ data in time relative to the velocity data to a maximum of $2 \mathrm{~s}$ to achieve the maximum numerical covariance (defined in terms of the maximum numerical flux) for $\left\langle w^{\prime} C^{\prime}\right\rangle$. This correction is necessary when the physical separation between the $\mathrm{O}_{2}$ sensor and the ADV measurement volume, and/or the sensor response time, result in a slight misalignment in the data (McGinnis et al. 2008, Donis et al. 2015). (9) By assuming law-of-the-wall velocity profiles, the mean sediment surface roughness $\left(z_{0}\right)$ was estimated as

$$
z_{0}=z \cdot \exp \left(-\kappa \cdot \frac{U}{u_{*}}\right)
$$

where $z$ is the measurement height above the benthic surface $(0.15 \mathrm{~m}), \kappa$ is the von Karman constant (0.41), and $U$ is the mean flow velocity magnitude (Berg et al. 2007).

The extracted 10 min EC fluxes were then carefully evaluated for their quality based on 3 criteria, namely by excluding periods with (1) large spikes or jumps in the $\mathrm{O}_{2}$ microsensor data, (2) rapid changes in flow direction and/or flow velocity magnitude, and (3) suppressed exchange rates of $\mathrm{O}_{2}$ due to insufficient turbulent mixing, which typically occurred when $U$ dropped below $\sim 2 \mathrm{~cm} \mathrm{~s}^{-1}$. Altogether, the screening process based on these 3 criteria typically resulted in the exclusion of $<15 \%$ of the measured 10 min $\mathrm{EC} \mathrm{O}_{2}$ fluxes.

\section{Dark benthic chamber $\mathrm{O}_{2}$ fluxes}

Areal rates of benthic $\mathrm{O}_{2}$ uptake $\left(\mathrm{mmol} \mathrm{m} \mathrm{m}^{-2} \mathrm{~h}^{-1}\right)$ were derived from the rate of change of $\mathrm{O}_{2}$ in the well-mixed incubated water phase over time as $(v / a) \times(\partial C / \partial t)$, where $v$ is the volume of the water phase in the chamber $\left(\mathrm{m}^{3}\right), a$ is the area of enclosed sediment $\left(\mathrm{m}^{2}\right), C$ is the $\mathrm{O}_{2}$ concentration $\left.(\mathrm{mmol} \mathrm{m})^{-3}\right)$, and $t$ is the incubation time (h) (Glud 2008).

\section{Rates of benthic productivity}

The rates of benthic productivity were calculated from each time series of the $\mathrm{EC} \mathrm{O}_{2}$ exchange rates. Night-time periods were identified as the periods when PAR was $\leq 1 \mu$ mol quanta $\mathrm{m}^{-2} \mathrm{~s}^{-1}$. Daytime periods comprised the remaining intervals. The $\mathrm{O}_{2}$ exchange during light (termed 'net daytime production', NDP) and $R$ were then computed from the EC time series in mmol $\mathrm{O}_{2} \mathrm{~m}^{-2} \mathrm{~h}^{-1}$ as a bulk average of the $\mathrm{O}_{2}$ fluxes during light and dark, respectively. Assuming a light-independent respiration rate, we also derived estimates for the benthic GPP $\left(\mathrm{mmol} \mathrm{O}_{2} \mathrm{~m}^{-2} \mathrm{~h}^{-1}\right)$ as GPP $=\mathrm{NDP}+|R|$. Acknowledging that the rate of $R$ during daytime typically is higher than that at night, we regard the GPP estimates presented herein as minimum values (Glud et al. 2009).

The autotrophic-heterotrophic balance of the benthic ecosystem (termed 'net ecosystem metabolism', NEM; mmol m $\mathrm{m}^{-2} \mathrm{~d}^{-1}$ ) was derived directly from the EC time series as the $24 \mathrm{~h}$ integration of the $\mathrm{O}_{2}$ flux. When more than $24 \mathrm{~h}$ of data was available (as was most often the case), the NEM was computed as a weighted average of the NDP and $R$ fluxes accounting for the number of day versus night hours. The NEM indicated whether sediment $\mathrm{O}_{2}$ production through photosynthesis balanced the various heterotrophic processes that directly or indirectly consume $\mathrm{O}_{2}$. Positive NEM values indicated a net $\mathrm{O}_{2}$ release by the benthic ecosystem (autotrophy) while negative NEM values indicated a net $\mathrm{O}_{2}$ uptake (heterotrophy) over a $24 \mathrm{~h}$ period.

\section{Benthic community light response}

The light dependency of the $\mathrm{EC}_{2}$ fluxes was evaluated using the photosynthesis versus irradiance $(P-E)$ relationship. The screened $10 \mathrm{~min} \mathrm{EC} \mathrm{O}_{2}$ fluxes covering at least one $24 \mathrm{~h}$ period were binned to $2 \mathrm{~h}$ intervals and plotted against the PAR data. This time interval was selected as a compromise between maintaining a high enough temporal resolution while minimizing the flow-induced effects and other nonsteady state dynamics within the BBL that confounded the $\mathrm{EC} \mathrm{O}_{2}$ fluxes on shorter time scales (Holtappels et al. 2013). The relationship between $\mathrm{EC} \mathrm{O}_{2}$ fluxes and PAR was investigated using various fitting functions, and from regression analyses it was established that the $P-E$ relationships were best explained by linear fits to the data. The compensation 
irradiance $\left(E_{\mathrm{c}}, \mu \mathrm{mol}\right.$ quanta $\left.\mathrm{m}^{-2} \mathrm{~s}^{-1}\right)$, that is, the PAR level at which GPP balances $R$, was subsequently derived from each linear fit as the $x$-intercept.

\section{RESULTS}

\section{Environmental conditions}

Bottom water temperature ranged from $16.6 \pm$ $0.4^{\circ} \mathrm{C}$ in summer to $6.3 \pm 0.2^{\circ} \mathrm{C}$ in winter. Bottom water salinity remained relatively constant during deployments but varied between 30.8 and 33.6 during the year. Bottom water $\mathrm{O}_{2}$ saturation was lowest in November ( $86 \pm 2 \%$ ) and highest in August (109 \pm $4 \%$ ) (Table 1). Variations in the bottom water $\mathrm{O}_{2}$ concentrations of up to $40 \mu \mathrm{mol} \mathrm{l}^{-1}$ ( $15 \%$ saturation) during deployments coincided with the tidal advection of $\mathrm{O}_{2}$-enriched waters from outer Loch Sween into Caol Scotnish. The daily integrated in situ PAR was lowest in February $\left(0.7\right.$ mol quanta $\left.\mathrm{m}^{-2} \mathrm{~d}^{-1}\right)$ and highest in April (5.5 mol quanta $\mathrm{m}^{-2} \mathrm{~d}^{-1}$ ).

\section{Eddy covariance measurements}

The narrow $(<100 \mathrm{~m})$ width of the side loch in Loch Sween and the tidally-driven flow resulted in wellconstrained hydrodynamics that allowed the divers to accurately align the EC instrument's longitudinal velocity component and the $\mathrm{O}_{2}$ microsensors within the main flow direction. Therefore rotation of the traverse velocity component during data processing was minimal and typically amounted to less than $\pm 20^{\circ}$. Care was taken to deploy the EC instruments level with the seabed such that the ADV tilt as measured by the instrument's internal compass was less than $\pm 3^{\circ}$. Under unidirectional flow conditions, the time lag correction required to identify a maximum numerical flux was typically 0.2 to $0.8 \mathrm{~s}$, which is in

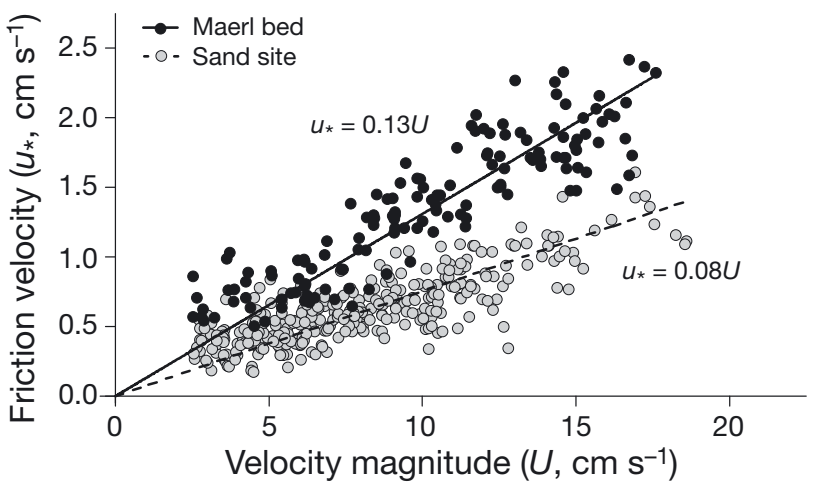

Fig. 3. Friction velocity $\left(u_{*}\right)$ as a function of flow velocity magnitude $(U)$ from parallel eddy covariance (EC) deployments over a $24 \mathrm{~h}$ period in April. Despite very similar flow magnitudes at both sites, $u_{*}$ was consistently higher at the maerl bed, indicating more vigorous turbulent mixing due to higher benthic surface roughness

good agreement with the $90 \%$ response time of the $\mathrm{O}_{2}$ microsensor. Linear relationships between the mean flow velocity magnitude (i.e. $U$ ) and $u_{*}$ indicate that a well-developed turbulent BBL was present during $\sim 90 \%$ of the sampling time at the 2 sites (Fig. 3). At low flow velocities $\left(<5 \mathrm{~cm} \mathrm{~s}^{-1}\right)$ the relationship between the flow velocity and $u_{*}$ deviated from linearity due to diminishing turbulent transport. When the flow velocity decreased below $\sim 2 \mathrm{~cm} \mathrm{~s}^{-1}$ the $\mathrm{O}_{2}$ fluxes were highly reduced due to insufficient turbulent mixing (Brand et al. 2008, Attard et al. 2014). Fluxes that fell within these periods amounted to $<10 \%$ of the total time series, and were excluded from further analyses.

We evaluated the sensitivity of the $\mathrm{EC}_{2}$ fluxes to coordinate transformation by comparing the flux estimates derived following coordinate rotation by the 'double' and 'planar' rotation methods, which gave the same results. Furthermore, we followed the procedure described by Holtappels et al. (2015) to estimate the artificial flux caused by the stirring-sensi-

Table 1. Data from the CTD deployments for the 5 measurement campaigns. Values for depth, temperature, salinity, and $\mathrm{O}_{2}$ are presented as a bulk average $( \pm \mathrm{SD})$ of the entire deployment. Daytime hours are defined as periods when seabed photosynthetically active radiation $(\mathrm{PAR})>1 \mu \mathrm{mol} \mathrm{m} \mathrm{m}^{-2} \mathrm{~s}^{-1}$. sat. = saturation

\begin{tabular}{|lccccccc|}
\hline $\begin{array}{l}\text { Measurement } \\
\text { campaign }\end{array}$ & $\begin{array}{c}\text { Depth } \\
(\mathrm{m})\end{array}$ & $\begin{array}{c}\text { Temperature } \\
\left({ }^{\circ} \mathrm{C}\right)\end{array}$ & Salinity & $\begin{array}{c}\mathrm{O}_{2} \\
\left(\mu \mathrm{mol} \mathrm{l}^{-1}\right)\end{array}$ & $\begin{array}{c}\mathrm{O}_{2} \\
(\% \text { sat. })\end{array}$ & $\begin{array}{c}\mathrm{PAR}^{2} \\
\left(\mathrm{~mol} \mathrm{~m}^{-2} \mathrm{~d}^{-1}\right)\end{array}$ & $\begin{array}{c}\text { Hours of } \\
\text { day/night }\end{array}$ \\
\hline Sep & $4.7 \pm 0.3$ & $14.6 \pm 0.2$ & $32.3 \pm 0.3$ & $245 \pm 20$ & $96 \pm 8$ & 0.95 & $12.8 / 11.2$ \\
Nov & $5.0 \pm 0.4$ & $10.1 \pm 0.3$ & $30.8 \pm 0.5$ & $244 \pm 7$ & $86 \pm 2$ & 1.17 & $11.2 / 12.8$ \\
Feb & $4.7 \pm 0.4$ & $6.3 \pm 0.2$ & $31.6 \pm 0.2$ & $310 \pm 6$ & $101 \pm 2$ & 0.70 & $8.5 / 15.5$ \\
Apr & $4.6 \pm 0.3$ & $9.6 \pm 0.4$ & $33.6 \pm 0.2$ & $302 \pm 11$ & $107 \pm 6$ & 5.48 & $14.3 / 9.7$ \\
Aug & $4.7 \pm 0.3$ & $16.6 \pm 0.4$ & $31.8 \pm 0.7$ & $270 \pm 9$ & $109 \pm 4$ & 3.29 & $14.5 / 9.5$ \\
\hline
\end{tabular}



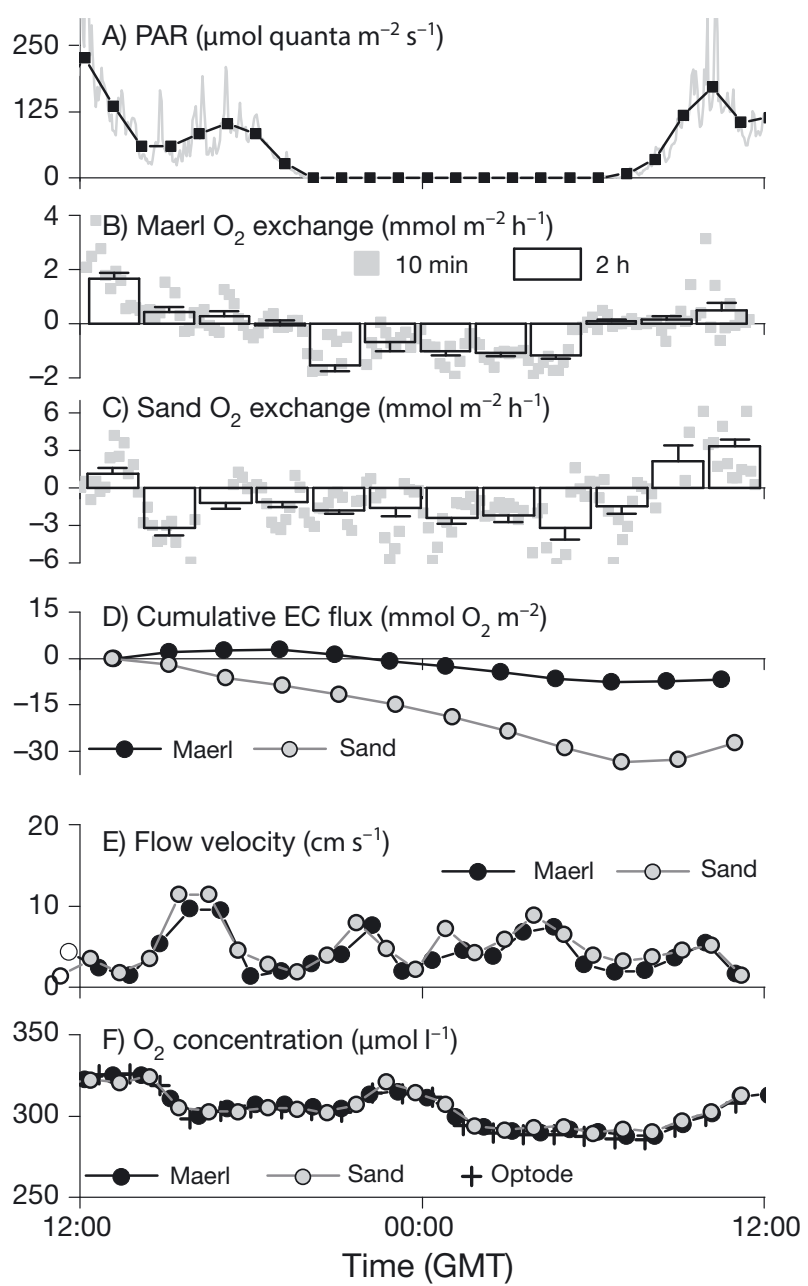

Fig. 4. A $24 \mathrm{~h}$ time series of eddy covariance (EC) $\mathrm{O}_{2}$ fluxes measured in parallel at (B) the maerl bed and (C) the adjacent ( $20 \mathrm{~m}$ apart) sand site in April. Positive fluxes indicate a net release of $\mathrm{O}_{2}$ from the seabed and negative fluxes indicate net $\mathrm{O}_{2}$ consumption. (A) The photosynthetically active radiation (PAR) availability was the main driver of $\mathrm{O}_{2}$ production, with $\mathrm{O}_{2}$ fluxes typically being positive during peak irradiance. (D) The $24 \mathrm{~h}$ integration of the $\mathrm{O}_{2}$ fluxes represents the net ecosystem metabolism (NEM). (E) The mean flow velocity was the second main control on the EC fluxes. (F) Flow velocity and $\mathrm{O}_{2}$ concentration show very good agreement between the 2 sites

tive $\mathrm{O}_{2}$ microsensors. To determine the theoretical upper limit of the flux bias due to stirring sensitivity, we selected periods of nighttime EC data that fulfilled the conditions required to induce a maximum flux bias, that is (1) the $\mathrm{O}_{2}$ microsensor being aligned with the main flow direction at an inclination of $\sim 60^{\circ}$, (2) high bottom-water $\mathrm{O}_{2}$ concentrations, and (3) vigorous turbulent mixing due to high flow velocity and/or high $z_{0}$ (Holtappels et al. 2015). Using MODEL 2 and a sensor stirring sensitivity of $0.5 \%$, we estimated the theoretical maximum flux bias to be on the order of 10 to $15 \%$ of the measured $\mathrm{EC} \mathrm{O}_{2}$ fluxes, which is well within the error margin of our flux estimates.

The well-developed turbulent BBL in Loch Sween maintained a steady benthic flux signal and allowed for detailed inferences to be made about the dynamics of the benthic $\mathrm{O}_{2}$ exchange rate in response to changing environmental conditions. Parallel deployment of 2 EC systems located $\sim 20 \mathrm{~m}$ apart from one another documented similar $\mathrm{O}_{2}$ flux dynamics, but substantial differences in the absolute exchange rates between the 2 sites that were exposed to very similar PAR, flow velocity magnitude, and bottom water $\mathrm{O}_{2}$ concentrations (Fig. 4). Typically, the $\mathrm{EC} \mathrm{O}_{2}$ fluxes showed a distinct diel response to the availability of PAR. During peak irradiance the EC $\mathrm{O}_{2}$ fluxes were positive, indicating net autotrophy. During the night, fluxes were negative. The diel signal in the data was overlain by extensive short-term variability, as seen in the 10 min fluxes in Fig. 4. This variability decreased substantially when averaged over $1 \mathrm{~h}$ or more. However, even on hourly time scales, the flow velocity magnitude was a major control on the EC fluxes. This was particularly evident in the nighttime data, where rates of $\mathrm{EC} \mathrm{O}_{2}$ uptake were enhanced by up to $\sim 10$-fold at the sand site and by $\sim 4$-fold at the maerl bed (Fig. 5). A seasonal trend in the slope of the regression between the nighttime $\mathrm{O}_{2}$ uptake rate and the mean flow velocity was noticeable, especially at the sand site. The magnitude of the slope increased from months with low to high benthic activity (Fig. 5). This result could reflect

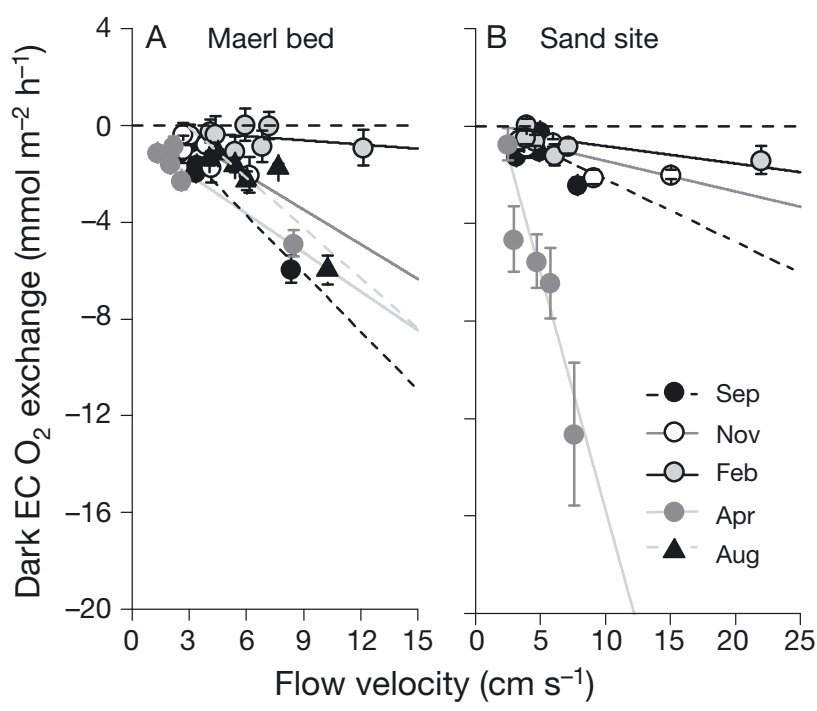

Fig. 5. Eddy covariance (EC) $\mathrm{O}_{2}$ exchange rates in darkness ( $2 \mathrm{~h}$ bins) as a function of the mean flow velocity at (A) the maerl bed and (B) the sand site. Error bars are SE $(n=12)$ 
the reduced state of the sediment, where reduced products from anaerobic decay processes accumulate in the surface sediments under low flow velocity, and are subsequently oxidized when the surface sediments are flushed with $\mathrm{O}_{2}$ under high flow velocities.

The $2 \mathrm{~h} \mathrm{EC} \mathrm{O}_{2}$ fluxes showed a good correlation with the in situ PAR during all seasons (Fig. 6, Table 2). There was no evidence of light saturation or photoinhibition in any of the 14 datasets (Fig. 6). Little light $\left(\sim 15 \mu \mathrm{mol}\right.$ quanta $\left.\mathrm{m}^{-2} \mathrm{~s}^{-1}\right)$ was required to drive a net autotrophic community response in winter. In the other campaigns the $E_{\mathrm{c}}$ was much higher, with peak values in September indicating a substantial heterotrophic component (Table 2). With the exception of February, the $E_{\mathrm{c}}$ at the sand site was consistently $\sim 2$-fold higher than that at the maerl bed, suggesting that less light was required to drive a net community autotrophic response at the maerl bed.

\section{Rates of $\mathrm{EC} \mathrm{O}_{2}$ exchange}

We derived the first estimates of NDP, $R, \mathrm{NEM}$, and GPP for a live maerl bed community using the noninvasive EC method as evidence for an active and productive benthic habitat. The maerl bed was a net source of $\mathrm{O}_{2}$ to the surrounding waters during daytime in February, April, and August, up to $0.6 \mathrm{mmol}$ $\mathrm{O}_{2} \mathrm{~m}^{-2} \mathrm{~h}^{-1}$. There was a net community consumption of $\mathrm{O}_{2}$ during daytime in September and November (Table 3). Mean EC $\mathrm{O}_{2}$ exchange rates in the dark ranged from $-0.6 \mathrm{mmol} \mathrm{O}_{2} \mathrm{~m}^{-2} \mathrm{~h}^{-1}$ in February to $-2.2 \mathrm{mmol} \mathrm{O}_{2} \mathrm{~m}^{-2} \mathrm{~h}^{-1}$ in September. By contrast, the sand site was on average heterotrophic or at metabolic balance during the daytime (range from 0.04 to $-1.0 \mathrm{mmol} \mathrm{O}_{2} \mathrm{~m}^{-2} \mathrm{~h}^{-1}$ ). The mean EC $\mathrm{O}_{2}$ exchange during the night at the sand site ranged from $-0.5 \mathrm{mmol} \mathrm{O}_{2} \mathrm{~m}^{-2} \mathrm{~h}^{-1}$ in February to $-3.7 \mathrm{mmol} \mathrm{O}_{2}$ $\mathrm{m}^{-2} \mathrm{~h}^{-1}$ in April. When integrated over $24 \mathrm{~h}$, both the maerl bed and the sand site were heterotrophic yearround, indicating that the benthic communities required additional inputs of organic matter originating from external sources. The maerl bed NEM ranged from -3.1 to $-33.1 \mathrm{mmol} \mathrm{O}_{2} \mathrm{~m}^{-2} \mathrm{~d}^{-1}$ and at the sand site it was from -3.1 to $-41.9 \mathrm{mmol} \mathrm{O}_{2} \mathrm{~m}^{-2} \mathrm{~d}^{-1}$.

The benthic phototrophic communities in Loch Sween were active during all measurement campaigns. The highest mean rates of GPP were measured in April (up to $3.3 \mathrm{mmol} \mathrm{O}_{2} \mathrm{~m}^{-2} \mathrm{~h}^{-1}$ ) when the integrated daily PAR was at its highest $(5.5 \mathrm{~mol}$ quanta $\mathrm{m}^{-2} \mathrm{~d}^{-1}$ ). However, even in winter when the duration of the daytime period was $\sim 1.7$ times shorter and daily PAR was $~ 8$-fold lower, the benthic phototrophs were still active. The highest mean rate of GPP for this period was measured at the maerl bed at $1.2 \mathrm{mmol} \mathrm{O}_{2} \mathrm{~m}^{-2} \mathrm{~h}^{-1}$, which is just $\sim 1.5$-fold lower than the April GPP estimate for the same site

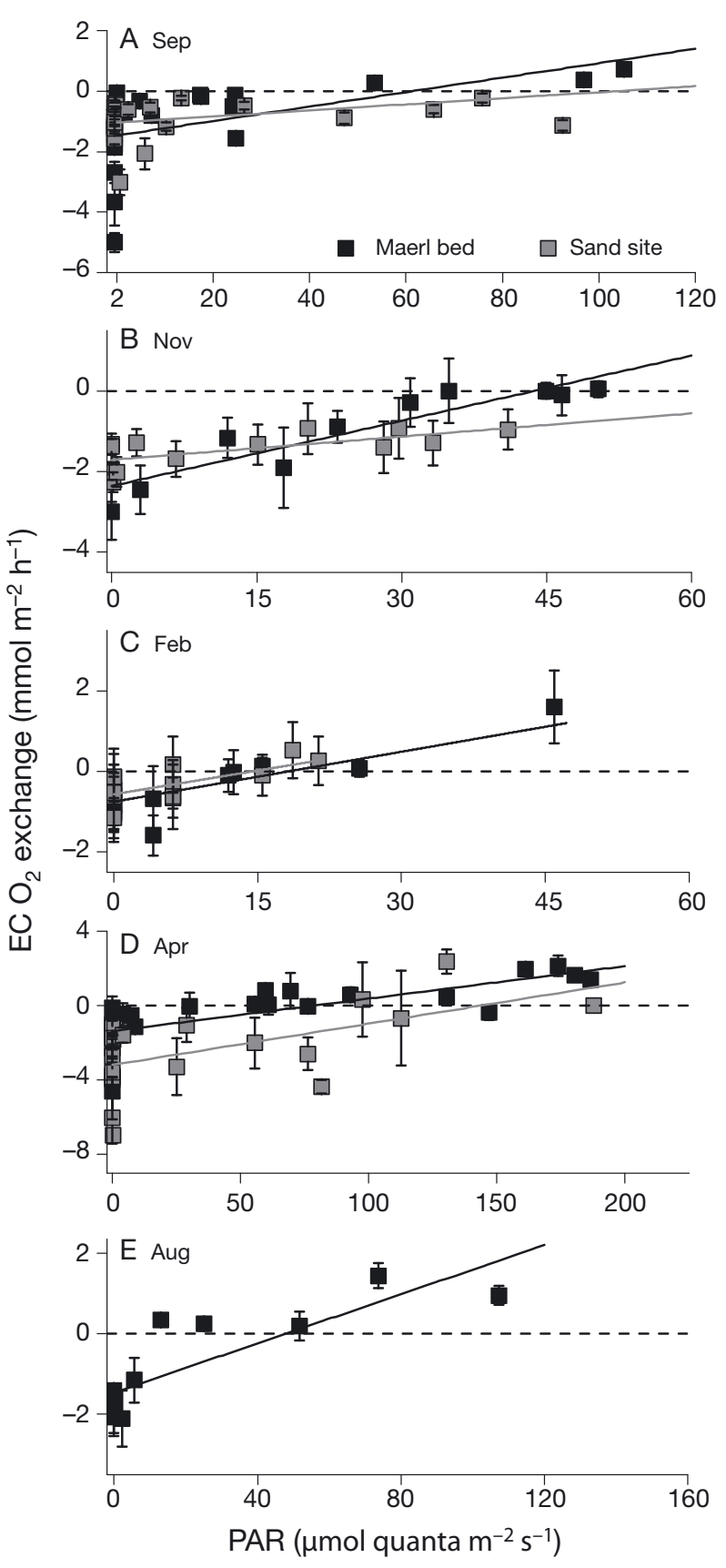

Fig. 6. Photosynthesis-irradiance $(P-E)$ relationships for both sites over the year. Linear regressions were fitted to $2 \mathrm{~h}$ binned eddy covariance (EC) $\mathrm{O}_{2}$ exchange rates $(\mathrm{n}=12)$. With the exclusion of the February datasets, the compensation irradiance at the maerl site was consistently $\sim 2$-fold lower than that at the sand site 


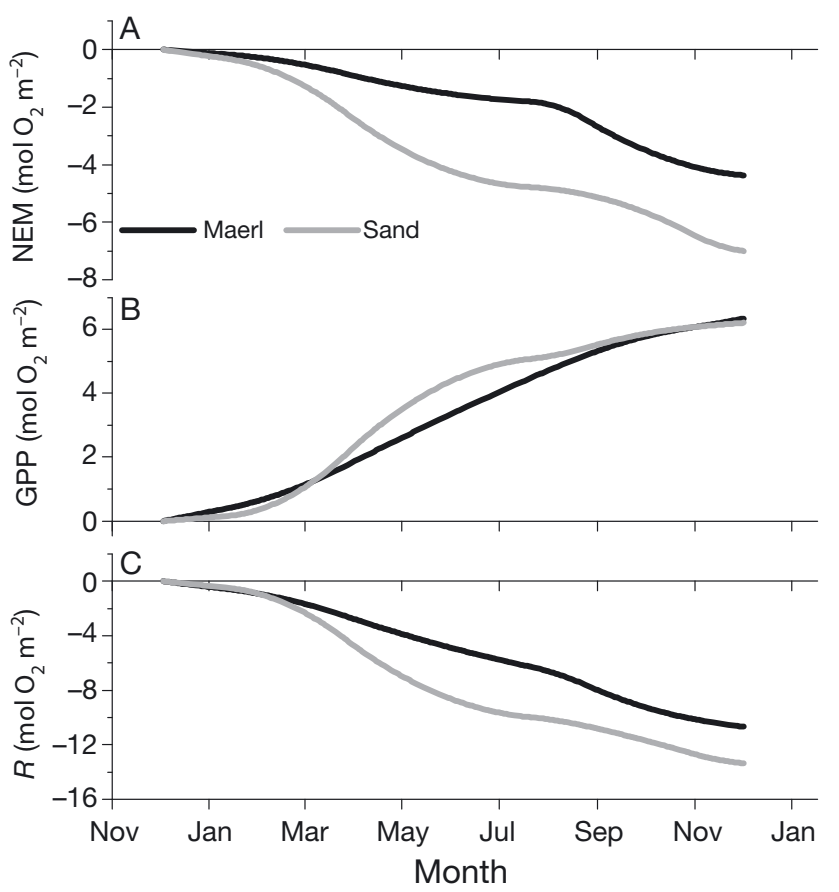

Fig. 7. Annual estimates of net (A) ecosystem metabolism (NEM), (B) gross primary productivity (GPP), and (C) respiration $(R)$ for the 2 sites as derived from seasonal eddy covariance (EC) measurements. The difference between the curves reflects the difference in the response of the benthic community between sites

(Table 3). Interestingly, despite the low light levels, the highest mean rate of net $\mathrm{O}_{2}$ release during daytime was measured at the maerl bed in February (NDP of $0.6 \mathrm{mmol} \mathrm{O}_{2} \mathrm{~m}^{-2} \mathrm{~h}^{-1}$ ).

The seasonally measured EC rates of NEM, GPP, and $R$ (Table 3 ) were used to derive cumulative estimates of these parameters over the year (Fig. 7). This analysis assumes that the rates measured during the individual measurement campaigns are representative of each season. Annual estimates of GPP were

Table 2. The fitting statistics of the linear photosynthesis versus irradiance $(P-E)$ relationships as fitted to $2 \mathrm{~h}$ averages of the eddy covariance (EC) $\mathrm{O}_{2}$ exchange rates. The slope is in mmol $\mathrm{O}_{2} \mathrm{~m}^{-2} \mathrm{~h}^{-1}\left(\mu \mathrm{mol} \text { quanta } \mathrm{m}^{-2} \mathrm{~s}^{-1}\right)^{-1}$, the intercept is in mmol $\mathrm{O}_{2} \mathrm{~m}^{-2} \mathrm{~h}^{-1}$, and the compensation irradiance $\left(E_{\mathrm{c}}\right)$ is in $\mu \mathrm{mol}$ quanta $\mathrm{m}^{-2} \mathrm{~s}^{-1}$. No $P-E$ relationship is available for the sand site in

August 2012 due to sensor damage incurred after $\sim 6 \mathrm{~h}$ of deployment

\begin{tabular}{|lccccccccc|}
\hline \multirow{2}{*}{$\begin{array}{l}\text { Measurement } \\
\text { campaign }\end{array}$} & \multicolumn{4}{c}{ Maerl site } & \multicolumn{4}{c}{ Sand site } \\
\hline Sep & Slope & Intercept & $E_{\mathrm{c}}$ & $\mathrm{R}^{2}$ & Slope & Intercept & $E_{\mathrm{c}}$ & $\mathrm{R}^{2}$ \\
Nov & 0.02 & -1.5 & 61 & 0.26 & 0.01 & -1.0 & 103 & 0.37 \\
Feb & 0.05 & -2.4 & 43 & 0.83 & 0.02 & -1.7 & 89 & 0.40 \\
Apr & 0.05 & -0.8 & 16 & 0.84 & 0.04 & -0.5 & 13 & 0.47 \\
Aug & 0.02 & -1.4 & 78 & 0.52 & 0.02 & -3.2 & 144 & 0.29 \\
& 0.03 & -1.5 & 48 & 0.68 & - & - & - & - \\
\hline
\end{tabular}

$\sim 6 \mathrm{~mol} \mathrm{O}_{2} \mathrm{~m}^{-2} \mathrm{yr}^{-1}$ for both sites. However, the sand site was overall more net heterotrophic, with a NEM of $-7 \mathrm{~mol} \mathrm{O}_{2} \mathrm{~m}^{-2} \mathrm{yr}^{-1}$ and a $R$ rate of $-13 \mathrm{~mol} \mathrm{O}_{2} \mathrm{~m}^{-2}$ $\mathrm{yr}^{-1}$. At the maerl bed NEM was $-4 \mathrm{~mol} \mathrm{O}_{2} \mathrm{~m}^{-2} \mathrm{yr}^{-1}$ and $R$ was $-11 \mathrm{~mol} \mathrm{O}_{2} \mathrm{~m}^{-2} \mathrm{yr}^{-1}$.

\section{Hydrodynamics and EC footprint characteristics}

The $z_{0}$ and $u_{*}$ estimates computed from the ADV velocity time series were variable between sites and between seasons. However, the measurements consistently indicated more intensified turbulent mixing at the maerl bed compared to the sand site (Fig. 3). Mean $( \pm \mathrm{SD}) z_{0}$ for the 5 campaigns at the sand site was $0.3 \pm 0.6 \mathrm{~cm}(\mathrm{n}=5)$, whereas at the maerl site it was $1.2 \pm 1.2 \mathrm{~cm}(\mathrm{n}=5)$. The characteristics of the EC flux footprint for the maerl bed calculated according to the parameterisation by Berg et al. (2007) suggest that the footprint was typically $\sim 15 \mathrm{~m}$ long with a width of $\sim 1 \mathrm{~m}$ and a region of maximum flux located $\sim 0.5 \mathrm{~m}$ upstream from the instrument. For the sand site, the flux footprint had an average length of $30 \mathrm{~m}$ with a width of $1 \mathrm{~m}$ and the region of maximum flux was $1.3 \mathrm{~m}$ upstream from the instrument. Due to the tidal reversal and therefore the reversal of the upstream location of the EC footprint, the $\mathrm{EC} \mathrm{O}_{2}$ exchange estimates for GPP, $R$, and NEM actually integrate an area of about twice the size of the footprint dimensions estimated above. Analyses of the $\mathrm{O}_{2}$ flux as a function of the flow direction suggested no substantial direction-dependent variations under the same light and flow conditions. The spatial extent of the maerl bed and the sand site was on the order of $100 \mathrm{~s}$ of $\mathrm{m}$ upstream of the EC instrument in either direction of flow, and therefore we can be confident that the flux estimates presented here integrate the activities of each respective benthic ecosystem.

Shallow-water benthic habitats are frequently characterised by spatial heterogeneity in the distribution of benthic organisms such as fauna and algae that may cause an uneven distribution of the flux signal within the EC footprint area. For flux measurements to be representative of the total benthic community activities, the spatial scales integrated by the EC measurements must be larger than the spatial scales of variation at the seabed. The former can be estimated with knowledge of the measurement height at which the EC measure- 
Table 3. Eddy covariance (EC) $\mathrm{O}_{2}$ exchange rates (mean $\pm \mathrm{SE}$ ). The values for light fluxes (i.e. net daytime production, NDP), dark fluxes (i.e. respiration, $R$ ), gross primary productivity (GPP), and the dark chambers are in $\mathrm{mmol} \mathrm{m}^{-2} \mathrm{~h}^{-1}$ whereas net ecosystem metabolism (NEM) values are in $\mathrm{mmol} \mathrm{m}^{-2} \mathrm{~d}^{-1} . \mathrm{MC}=$ measurement campaign

\begin{tabular}{|c|c|c|c|c|c|c|c|c|c|c|c|c|}
\hline \multirow[t]{2}{*}{$\mathrm{MC}$} & \multicolumn{5}{|c|}{$\longrightarrow$ EC maerl bed } & \multirow{2}{*}{$\begin{array}{c}\text { Maerl } \\
\text { chambers } \\
(R)\end{array}$} & \multicolumn{5}{|c|}{ EC sand site } & \multirow{2}{*}{$\begin{array}{c}\text { Sand } \\
\text { chambers } \\
(R)\end{array}$} \\
\hline & \multicolumn{2}{|c|}{$\begin{array}{cc}\text { Dataset } & \text { NDP } \\
\text { length }(\mathrm{h}) & \end{array}$} & $R$ & GPP & NEM & & $\begin{array}{l}\text { Dataset } \\
\text { length }(\mathrm{h})\end{array}$ & h) & $R$ & GPP & NEM & \\
\hline Sep & 44 & $-0.69 \pm 0.4$ & $-2.16 \pm 0.4$ & 1.49 & -33.1 & $-2.36 \pm 0.19$ & 39 & $0.04 \pm 0.3$ & $-1.09 \pm 0.5$ & 1.13 & -11.7 & $-1.03 \pm 0.05$ \\
\hline Nov & 24 & $-0.30 \pm 0.3$ & $-0.95 \pm 0.2$ & 0.65 & -15.5 & $-1.05 \pm 0.13$ & $26-$ & $-0.98 \pm 0.2$ & $-1.42 \pm 0.5$ & 0.44 & -29.2 & $-1.07 \pm 0.28$ \\
\hline Feb & 26 & $0.58 \pm 0.3$ & $-0.58 \pm 0.1$ & 1.16 & -4.1 & $-1.05 \pm 0.38$ & 24 & $-0.03 \pm 0.1$ & $-0.48 \pm 0.2$ & 0.45 & -7.8 & $-0.56 \pm 0.18$ \\
\hline Apr & 51 & $0.15 \pm 0.3$ & $-1.63 \pm 0.3$ & 1.78 & -13.7 & $-1.06 \pm 0.19^{\mathrm{a}}$ & $43-$ & $-0.42 \pm 1.5$ & $-3.69 \pm 1.3$ & 3.27 & -41.9 & $-1.07 \pm 0.64^{\mathrm{a}}$ \\
\hline Aug & 24 & $0.47 \pm 0.2$ & $-1.04 \pm 0.2$ & 1.51 & -3.1 & $-1.11 \pm 0.17$ & $6-$ & $-0.08 \pm 0.6$ & - & $0.37^{\mathrm{b}}$ & -3.1 & $-0.45 \pm 0.13$ \\
\hline
\end{tabular}

ments were performed (i.e. $0.15 \mathrm{~m}$ ) and the average $z_{0}$ derived from the ADV measurements (Rheuban \& Berg 2013). The heterogeneity of the seabed surface can be approximated from high-resolution images of the seabed. In short, a low measurement height and a high $z_{0}$ would result in a rapid transfer of the benthic flux signal from the seabed to the EC sensors, and would thus integrate small spatial scales. Following the procedure described by Rheuban \& Berg (2013), we deduced that the spatial scales that our EC measurements integrated ('patch sizes' of $\sim 30 \mathrm{~cm}$ at the maerl bed and $\sim 50 \mathrm{~cm}$ at the sand site) were large relative to the spatial scales of variation within the EC footprint area. Therefore, errors induced due to spatial variability were small $(<5 \%)$, and our EC setup was optimal for deriving $\mathrm{O}_{2}$ exchange rates that are representative of the total benthic communities at both sites.

\section{Benthic chamber measurements}

The benthic $\mathrm{O}_{2}$ exchange rates from the chamber deployments during the night revealed $\mathrm{O}_{2}$ uptake rates at the maerl bed ranging from a mean $( \pm \mathrm{SE})$ of $-1.0 \pm 0.1 \mathrm{mmol} \mathrm{m}^{-2} \mathrm{~h}^{-1}(\mathrm{n}=3)$ in November to $-2.4 \pm$ $0.2 \mathrm{mmol} \mathrm{m}^{-2} \mathrm{~h}^{-1}(\mathrm{n}=4)$ in September (Table 3). At the sand site, the range was from $-0.5 \pm 0.4 \mathrm{mmol} \mathrm{O}_{2}$ $\mathrm{m}^{-2} \mathrm{~h}^{-1}(\mathrm{n}=4)$ in February to $-1.1 \pm 0.2 \mathrm{mmol} \mathrm{O}_{2} \mathrm{~m}^{-2}$ $\mathrm{h}^{-1}(\mathrm{n}=4)$ in April. Variations in the resolved $\mathrm{O}_{2}$ exchange rate between the replicate $0.1 \mathrm{~m}^{2}$ chambers were less than $\sim 2$-fold at both sites in September and November. However in February, April, and August the replicate chambers resolved highly variable $\mathrm{O}_{2}$ exchange rates that varied by up to $\sim 6$-fold at the maerl bed in February (from -0.3 to $-1.9 \mathrm{mmol}$ $\mathrm{m}^{-2} \mathrm{~h}^{-1}$ ) and by a factor of $\sim 8$ at the sand site in April (from -0.4 to $-3.0 \mathrm{mmol} \mathrm{m}^{-2} \mathrm{~h}^{-1}$ ).

\section{DISCUSSION}

\section{Metabolism of a live maerl bed}

Detailed studies on the metabolism of isolated red coralline algae indicate low rates of photosynthesis and respiration in line with their slow growth rate of $<1 \mathrm{~mm} \mathrm{yr}^{-1}$ (Roberts et al. 2002, Blake \& Maggs 2003, Martin et al. 2013). Growth rates of Lithothamnion glaciale in Loch Sween have been estimated at around $0.2 \mathrm{~mm} \mathrm{yr}^{-1}$ (Burdett et al. 2011). However, live maerl beds increase the substratum heterogeneity and provide structurally complex habitats that are colonized by a large diversity of both autotrophic and heterotrophic organisms (Barbera et al. 2003, Teichert 2014). Therefore, it is likely that the respiration and primary production of the maerl themselves only represent a small fraction of the total benthic community $\mathrm{C}$ turnover rates. The highly porous maerl framework is ventilated by the turbulent water flow, and particles, nutrients, and plankton can easily flow through the complex cavities and sustain community metabolism. The ventilation process, the complex structure of the maerl bed, and the spatiotemporal variability in $\mathrm{O}_{2}$ production and consumption introduce various assumptions when quantifying the GPP, $R$, and NEM using benthic chambers that could potentially compromise the estimates. In contrast to this, the EC method is non-invasive and the measurements integrate a large footprint area. This study is the first of its kind to apply this method to document community $\mathrm{O}_{2}$ dynamics and quantify benthic primary productivity and $\mathrm{C}$ turnover in such environments.

The non-invasive EC measurements revealed substantial benthic primary production in the maerl bed year-round. To our knowledge, there exists just one other seasonal study on benthic $\mathrm{O}_{2}$ exchange in a 
maerl bed community, conducted in the temperate Bay of Brest, France, using in situ benthic chambers (Martin et al. 2007). The reported GPP values for that site range from $\sim 4$ to $134 \mathrm{mmol} \mathrm{O}_{2} \mathrm{~m}^{-2} \mathrm{~d}^{-1}$ between winter and summer, with an annual rate of $24.5 \mathrm{~mol} \mathrm{O}_{2} \mathrm{~m}^{-2} \mathrm{yr}^{-1}$. This rate is $\sim 4$-fold higher than the yearly GPP estimate for the maerl bed community in Loch Sween of $\sim 6 \mathrm{~mol} \mathrm{O}_{2} \mathrm{~m}^{-2} \mathrm{yr}^{-1}$. However, the PAR available for benthic photosynthesis at our study site was up to $\sim 8$-fold lower than that reported by Martin et al. (2007) for the Bay of Brest. This difference could explain much of the variations in the GPP between the 2 temperate sites. In contrast with phytoplankton productivity, benthic primary productivity is typically limited by PAR rather than nutrient availability (Barranguet et al. 1998, Gattuso et al. 2006). This inference is supported by our in situ EC measurements, which document a linear increase of the $\mathrm{EC}_{2}$ fluxes in response to increasing light levels at the seabed. Therefore, a maximum rate of benthic $\mathrm{O}_{2}$ production was not observed, even when seabed PAR reached $\sim 300 \mu \mathrm{mol}$ quanta $\mathrm{m}^{-2} \mathrm{~s}^{-1}$ in summer (Fig. 6, Table 2).

Despite substantial benthic primary production, the benthic $\mathrm{O}_{2}$ consumption exceeded $\mathrm{O}_{2}$ production in the maerl bed over a diel period, and the maerl bed community was net heterotrophic during each sampling campaign. Even though the biomass of live maerl thalli can be substantial, its contribution to the food web is thought to be low due to the very low organic content of its tissues $(<6 \%$; N. A. Kamenos pers. obs.) and the limited number of grazers that are able to feed directly on live maerl fragments (Graham 1988, Grall et al. 2006, Martin et al. 2007). Most of the $\mathrm{C}$ required by the benthic communities was therefore likely synthesized by epiphytic macroalgae and microphytobenthos, but the communities required an additional input of $\mathrm{C}$ from the surrounding environment amounting to $\sim 4 \mathrm{~mol} \mathrm{C} \mathrm{m}{ }^{-2} \mathrm{yr}^{-1}$ (assuming a respiration quotient of 1.0). These inferences are consistent with the seasonal study in the Bay of Brest, where despite a substantial annual benthic GPP, the maerl community was net heterotrophic and required an additional $\mathrm{C}$ input of $14 \mathrm{~mol} \mathrm{~m}^{-2} \mathrm{yr}^{-1}$ (167 $\mathrm{g} \mathrm{C} \mathrm{m}^{-2} \mathrm{yr}^{-1}$ ) (Martin et al. 2007).

The annual $\mathrm{C}$ deficit in Loch Sween was likely a result of sedimentation and entrapment of phytoplankton, and to a lesser extent, terrestrially derived material from the catchment area. The potential importance of external inputs of organic matter to the maerl bed is substantiated by the high densities of the suspension-feeding brittle stars Ophiothrix fragilis associated with the live maerl in Loch Sween
(Fig. 1C). The heterogeneous substrate of live maerl thalli in combination with the hydrodynamics at the seabed and the high concentration of particles in the water column make this habitat ideal for suspensionfeeding brittle stars (Davoult \& Gounin 1995). This may explain the high densities of $O$. fragilis at the maerl bed compared to the adjacent sandy habitat that was instead dominated by the deposit feeding brittle star Ophiocomina nigra (Fig. 1).

\section{Carbon turnover in maerl versus sandy sediments}

To date, studies comparing maerl beds with adjacent bare sediments have focused on the importance of the maerl structure for local benthic biodiversity (Barbera et al. 2003, Kamenos et al. 2003, Teichert 2014). No previous studies have compared the biogeochemical functioning of the maerl bed to adjacent bare sediments. The 2 habitats we investigated were located at the same depth and within $\sim 20 \mathrm{~m}$ of one another, and therefore experienced the same environmental conditions of PAR, flow velocity, $\mathrm{O}_{2}$ concentrations, and temperature. This provided an ideal opportunity for detailed comparisons of community based $\mathrm{C}$ turnover and their controls at these 2 contrasting sites.

The EC measurements revealed very similar annual GPP for both sites: $\sim 6 \mathrm{~mol} \mathrm{O}_{2} \mathrm{~m}^{-2} \mathrm{yr}^{-1}$ (Fig. 7). These rates are comparable to the annual depthintegrated phytoplankton productivity in the $<35 \mathrm{~m}$ deep photic zone measured at 3 nearby locations using ${ }^{14} \mathrm{C}$-labelled bicarbonate incubations (range from 10 to $17 \mathrm{~mol} \mathrm{C} \mathrm{m}{ }^{-2} \mathrm{yr}^{-1}$; Rees et al. 1995). Despite a net light under-saturation of the benthic communities, the seabed is an important component for primary production in the shallow water ecosystems of the Loch Sween Marine Protected Area.

The benthic GPP rates presented above must be regarded as minimum estimates, since computing the GPP from $\mathrm{O}_{2}$ exchange measurements invokes the assumption that $\mathrm{O}_{2}$ consumption is equal during day and night (Glud et al. 2009). During daytime, the rate of $\mathrm{O}_{2}$ consumption is typically 1.4 to 1.8 -fold higher as a result of (1) deeper $\mathrm{O}_{2}$ penetration and hence a larger volume of sediment that can support $\mathrm{O}_{2}$ consumption, and (2) elevated turnover of leaching labile photosynthesates (Epping \& Jørgensen 1996, Fenchel \& Glud 2000). Evidence of this process within $\mathrm{EC} \mathrm{O}_{2}$ exchange time series is often inferred from high rates of $\mathrm{O}_{2}$ consumption at dusk, when photosynthetic activity ceases and the leftover labile pool of photosynthesates is efficiently turned over 
within the first hours of the night (Glud et al. 2010, Long et al. 2013, Rheuban et al. 2014). This feature was also evident in the EC datasets from both the maerl bed and the sand site (Fig. 4B), where the rates of $\mathrm{O}_{2}$ uptake at dusk frequently were $\sim 2$-fold higher than the corresponding values later in the night. No changes in flow velocity, flow direction, bottom water temperature, or $\mathrm{O}_{2}$ concentration could otherwise explain this difference. However, we cannot exclude that temporal shifts in fauna activity also could have contributed to the elevated rates of $\mathrm{O}_{2}$ consumption at sunset, a process that has been observed in other shallow water habitats (Wenzhöfer \& Glud 2004).

The availability of PAR at the seabed was the main driver of benthic $\mathrm{O}_{2}$ production at both sites (Figs. 4 \& $6)$. The community $E_{\mathrm{C}}$ that is, the PAR level at which GPP balances $R$, exhibited a distinct seasonal trend (Table 2). At both sites, $E_{\mathrm{c}}$ was lowest in winter $\left(\sim 15 \mu \mathrm{mol}\right.$ quanta $\left.\mathrm{m}^{-2} \mathrm{~s}^{-1}\right)$. During the remaining seasons the $E_{\mathrm{c}}$ at the sand site was consistently $\sim 2$ times higher than that at the maerl bed. The higher $E_{\mathrm{c}}$ at the sand site was largely a result of flow-induced stimulation of $\mathrm{O}_{2}$ uptake during the day. At the maerl bed, daytime EC measurements were largely unaffected by flow velocity. However at the more permeable sand site, high mean flow velocities $\left(>5 \mathrm{~cm} \mathrm{~s}^{-1}\right)$ induced a negative $\mathrm{O}_{2}$ exchange rate that deviated substantially from $\mathrm{O}_{2}$ exchange rates measured at similar irradiances under lower flow velocities $\left(<5 \mathrm{~cm} \mathrm{~s}^{-1}\right)$ (Fig. 8). Therefore, the net sediment $\mathrm{O}_{2}$ release from the photic zone within the sediments under high irradiances was offset by a higher flowinduced uptake rate of $\mathrm{O}_{2}$ as a result of deep and rapid pore-water advection (Berg et al. 2013).

A key component of the biogeochemical functioning of benthic environments is the entrapment and degradation of newly settled organic material by sediments and fauna (Middelburg et al. 2005). Both of these processes are included within the EC flux measurements. Interestingly, even though the maerl bed had high densities of suspension-feeding brittle stars and a highly porous upper framework, the C degradation at the sand site still exceeded that of the maerl bed ( $\mathrm{C}$ deficit of $\sim 4 \mathrm{~mol} \mathrm{~m}{ }^{-2} \mathrm{yr}^{-1}$ at the maerl bed and $\sim 7 \mathrm{~mol} \mathrm{~m}^{-2} \mathrm{yr}^{-1}$ at the sand site). This result could reflect a higher entrapment efficiency of organic material at the more permeable sand site. Highly permeable sediments have been termed 'biocatalytic filters' for their ability to effectively entrap and decompose organic matter (Huettel et al. 2014, McGinnis et al. 2014). However, for hydraulic connectivity in the surface sediments to persist, incorporation of fine sediments into the sand matrix must be

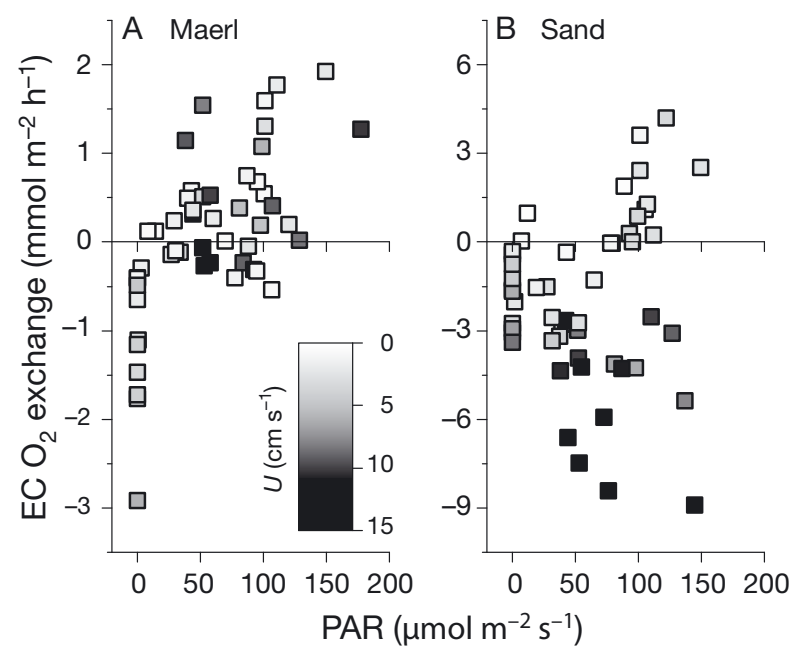

Fig. 8. Photosynthesis-irradiance $(P-E)$ relationship for both sites showing the effect of flow velocity on discrete $10 \mathrm{~min}$ eddy covariance (EC) $\mathrm{O}_{2}$ exchange rates over an $8 \mathrm{~h}$ period in April. The flow had little to no effect on the exchange rates at the maerl bed during the day, but substantially stimulated an $\mathrm{O}_{2}$ uptake that offset the net photosynthetic $\mathrm{O}_{2}$ release at the more permeable sandy site

kept low due to low deposition rates or by repeated cycles of current- and wave-induced sediment resuspension and winnowing. Erosion of sands occurs above a critical $u_{*}$ threshold of $\sim 0.7 \mathrm{~cm} \mathrm{~s}^{-1}$ (Wiberg \& Smith 1987), which corresponds to a flow velocity of $\sim 5 \mathrm{~cm} \mathrm{~s}^{-1}$ at the maerl bed and $\sim 9 \mathrm{~cm} \mathrm{~s}^{-1}$ at the sand site. This is well below the maximal $u_{*}$ values observed at both sites during a typical tidal cycle in Loch Sween (Fig. 3).

\section{Comparison to global benthic primary productivity estimates}

Globally, complex light-exposed benthic ecosystems such as maerl beds and permeable sediments cover large areas of the inner shelf region and contribute substantially to local and regional primary production (Gattuso et al. 2006). Our range of GPP estimates for the 2 sites in Loch Sween (from 0.7 to $1.8 \mathrm{mmol} \mathrm{O}_{2} \mathrm{~m}^{-2} \mathrm{~h}^{-1}$ for the maerl bed and from 0.4 to $3.3 \mathrm{mmol} \mathrm{O}_{2} \mathrm{~m}^{-2} \mathrm{~h}^{-1}$ for the sand site) exceed the global average estimates for benthic microalgal productivity for the 0 to $5 \mathrm{~m}$ depth range in temperate regions ( 0.8 $\mathrm{mmol} \mathrm{C} \mathrm{m}^{-2} \mathrm{~h}^{-1}$; Cahoon 1999). However, the Loch Sween GPP estimates are at the lower end of those for the maerl bed in the Bay of Brest, France (range from 0.2 to $5.6 \mathrm{mmol} \mathrm{O}_{2} \mathrm{~m}^{-2} \mathrm{~h}^{-1}$; Martin et al. 2007), as well as EC-derived GPP estimates for shallow (3 to $8 \mathrm{~m}$ deep) benthic habitats in a 
southwest Greenland fjord (range from 0.1 to $5.7 \mathrm{mmol} \mathrm{O}_{2} \mathrm{~m}^{-2} \mathrm{~h}^{-1}$; Glud et al. 2010, Attard et al. 2014). EC-derived GPP estimates in temperate seagrass beds are substantially higher (range from 2 to $20 \mathrm{mmol} \mathrm{O}_{2} \mathrm{~m}^{-2} \mathrm{~h}^{-1}$; Rheuban et al. 2014), as are those for tropical coral reefs (up to $40 \mathrm{mmol} \mathrm{O}_{2} \mathrm{~m}^{-2}$ $\mathrm{h}^{-1}$; Long et al. 2013). Therefore, while the benthic communities of Loch Sween contribute substantially to local and regional primary production, the GPP rates are somewhat modest when compared to other shallow benthic habitats.

\section{Benthic chamber versus EC measurements}

There are a growing number of studies within the literature comparing the benthic community $\mathrm{O}_{2}$ exchange rates as resolved using chamber incubations versus the EC method. The 2 approaches have been reported to provide similar rates for cohesive sediments that lack large conspicuous macrofaunal species, giving confidence in the 2 measurement techniques (Berg et al. 2003, 2009). Many of the studies that employed both methods in more complex benthic systems such as permeable sands and in those dominated by large macrofauna also suggest good agreement between the average rates (Table 4). The largest discrepancies between the 2 methods (up to a factor of $\sim 4$ ) are reported for highly permeable sediments under dynamic flow conditions (Berg et al. 2013). For coarse-grained sediments, the interaction between the boundary-layer flows and the sediment topography results in small lateral pressure gradients that drive an advective-dominated $\mathrm{O}_{2}$ flux into the permeable seabed (Huettel \& Gust 1992, Huettel et al. 2003). Benthic chambers attempt to artificially recreate these conditions but may not fully capture the in situ dynamics. Therefore, we could expect a wide range of reported values for the ECversus chamber-resolved $\mathrm{O}_{2}$ fluxes in permeable environments (EC:chamber range from 0.5 to 4.1 ; Table 4).

In this study, we obtained the benthic $\mathrm{O}_{2}$ uptake rate from parallel measurements using multiple benthic chambers and EC in the dark at 2 contrasting shallow-water sites and in different seasons. To date, these measurements constitute the most extensive benthic chamber versus EC comparisons. The benthic ecosystem of Loch Sween is comprised principally of permeable sediments and a patchy distribution of large epifauna and macroalgae (Fig. 1B,C), which suggests substantial horizontal spatial heterogeneity in the $\mathrm{O}_{2}$-consuming processes. This is reflected in the large variations between replicate $0.1 \mathrm{~m}^{2}$ chambers by up to a factor of $\sim 6$ at the maerl bed and $\sim 8$ at the sand site. Despite large variability between individual chambers, the mean rates of $\mathrm{O}_{2}$ uptake in the dark estimated from the chamber

Table 4. Studies in various benthic settings that employed both chamber and eddy covariance (EC) measurements to estimate the benthic $\mathrm{O}_{2}$ uptake rate for non-photic sediments, classified as 'muds' and 'sands'. Flow velocity is measured by the EC instrument 10 to $15 \mathrm{~cm}$ above the seabed surface. Units for benthic chamber surface area are in $\mathrm{m}^{2}$. Whenever seasonal measurements are available, the $\mathrm{EC}$ :chamber $(\mathrm{EC}: \mathrm{Ch})$ is presented as a range of values obtained, and the overall mean is presented in brackets. The April measurements in Loch Sween were excluded from the overall average due to the benthic chamber measurements being compromised during this campaign (see 'Materials and methods: Benthic chamber measurements')

\begin{tabular}{|c|c|c|c|c|c|c|}
\hline $\begin{array}{l}\text { Sediment } \\
\text { type }\end{array}$ & $\mathrm{EC}: \mathrm{Ch}$ & $\begin{array}{l}\text { Depth } \\
(\mathrm{m})\end{array}$ & $\begin{array}{l}\text { Flow velocity } \\
\quad\left(\mathrm{cm} \mathrm{s}^{-1}\right)\end{array}$ & $\begin{array}{c}\text { Chambers } \\
\text { (no. of replicates, } \\
\text { surface area) }\end{array}$ & Location & Study \\
\hline \multirow[t]{4}{*}{ Muds } & 1.4 & 12 & 2 & $4,0.1$ & Aarhus Bay, Denmark & Berg et al. (2003) \\
\hline & 1.1 & 8 & $2-4$ & $6,0.1$ & Limfjord, Denmark & Berg et al. (2003) \\
\hline & 0.9 & 1450 & $1-3$ & $2,0.1$ & Sagami Bay, Japan & Berg et al. (2009) \\
\hline & 0.9 & 50 & $1-13$ & $4,0.1$ & Loch Etive, Scotland & Glud et al. unpubl. data \\
\hline \multirow[t]{7}{*}{ Sands } & 4.1 & 3 & 31 & $5,0.1$ & Wakulla River, USA & Berg et al. (2013) \\
\hline & 2.2 & 1 & $0-5$ & $5,0.1$ & Florida, USA & Berg et al. $(2015)^{\mathrm{b}}$ \\
\hline & 1.5 & 74 & $1-10$ & $1,0.1$ & Tommeliten, North Sea & McGinnis et al. (2014) \\
\hline & 1.1 & 107 & $3-10$ & $1,0.2$ & Half Moon Bay, USA & Johnson et al. (2011) \\
\hline & $0.9-1.3(1.2)$ & 5 & $2-20$ & $10,0.1$ & Loch Sween, Scotland & This study ${ }^{\mathrm{a}}$ \\
\hline & $0.7-0.8(0.8)$ & 95 & $3-17$ & $3,0.2$ & Monterey Bay, USA & Johnson et al. $(2011)^{a}$ \\
\hline & 0.5 & 80 & $0-13$ & $2,0.04$ & Oregon Shelf, USA & Reimers et al. (2012) \\
\hline Maerl bed & $0.6-0.9(0.8)$ & 5 & $2-20$ & $16,0.1$ & Loch Sween, Scotland & This study ${ }^{\mathrm{a}}$ \\
\hline
\end{tabular}


deployments in most cases compared well to those resolved in parallel by EC (Table 3). At the maerl bed, the ratio of the mean $( \pm \mathrm{SD})$ benthic $\mathrm{O}_{2}$ uptake rate as resolved by $\mathrm{EC}$ to the chambers ranged from $0.6 \pm 0.1(\mathrm{n}=4)$ to $0.9 \pm 0.3(\mathrm{n}=5)$ with an overall average of $0.8 \pm 0.2(\mathrm{n}=16)$. At the sand site, the range was from $0.9 \pm 0.1(\mathrm{n}=4)$ to $1.3 \pm 0.5(\mathrm{n}=2)$ with an overall average of $1.2 \pm 0.2(\mathrm{n}=10)$. These values are well within the range of the ratios typically reported for coastal aphotic benthic systems (between 0.8 and 1.5 ; Table 4 ).

The agreement between the EC- and chamberresolved measurements presented here lends credibility to the application of both methods in complex environments. However, the large variation between replicate chambers indicates that replication is critical to integrate larger spatial scales and resolve an $\mathrm{O}_{2}$ uptake rate that is representative of the total benthic community. The number of replicate chambers required varies between sites and depends on the amount of heterogeneity present. For example, in a simulation study performed by Glud \& Blackburn (2002) for a deep-sea cohesive sediment dominated by relict burrow structures (30 to 120 burrows $\mathrm{m}^{-2}$ ), 4 replicate $0.1 \mathrm{~m}^{2}$ benthic chambers were able to determine the benthic $\mathrm{O}_{2}$ uptake rate to within $~ 95 \%$ accuracy. This was reduced to $\sim 80 \%$ when the same analysis was applied at a more heterogeneous coastal cohesive site dominated by sparsely distributed large epifauna (Glud \& Blackburn 2002). Logistical constraints frequently limit deployment of multiple benthic chambers, and here the EC method holds a clear advantage in its ability to integrate larger spatial scales and to better resolve temporal dynamics in the $\mathrm{O}_{2}$ flux. In this respect, the EC method represents a powerful new approach for detailed studies on benthic $\mathrm{O}_{2}$ dynamics in complex coastal environments such as maerl beds and other permeable settings.

Acknowledgements. We thank Anni Glud for constructing the oxygen microelectrodes used in this study, Daniel F. McGinnis for providing the SOHFEA software package for EC flux calculations, and Peter Slann for on-site facility access. We thank 3 anonymous reviewers whose thorough and constructive comments helped improve the manuscript. This project was financed by the Commission for Scientific Research in Greenland (KVUG; GCRC6507), the UK Natural Environmental Research Council (NERC, NE/F018612/1, NE/F0122991/1, NE/G006415/1, NE/H525303/1), the European Research Council through an Advanced Grant (ERC-2010-AdG20100224), the Danish National Research Foundation (DNRF53), a Marine Alliance for Science \& Technology for Scotland (MASTS) Fellowship to H.L.B., and a Royal Society of Edinburgh / Scottish Government Fellowship to N.A.K.

\section{LITERATURE CITED}

Attard KM, Glud RN, McGinnis DF, Rysgaard S (2014) Seasonal rates of benthic primary production in a Greenland fjord measured by aquatic eddy correlation. Limnol Oceanogr 59:1555-1569

> Barbera C, Bordehore C, Borg JA, Glémarec M and others (2003) Conservation and management of northeast Atlantic and Mediterranean maerl beds. Aquatic Conserv 13:S65-S76

Barranguet C, Kromkamp J, Peene J (1998) Factors controlling primary production and photosynthetic characteristics of intertidal microphytobenthos. Mar Ecol Prog Ser 173:117-126

> Berg P, Huettel M (2008) Monitoring the seafloor using the noninvasive eddy correlation technique: integrated benthic exchange dynamics. Oceanography 21:164-167

- Berg P, Roy H, Janssen F, Meyer V, Jorgensen BB, Huettel M, de Beer D (2003) Oxygen uptake by aquatic sediments measured with a novel non-invasive eddy-correlation technique. Mar Ecol Prog Ser 261:75-83

Berg P, Roy H, Wiberg PL (2007) Eddy correlation flux measurements: the sediment surface area that contributes to the flux. Limnol Oceanogr 52:1672-1684

Berg P, Glud RN, Hume A, Stahl H, Oguri K, Meyer V, Kitazato H (2009) Eddy correlation measurements of oxygen uptake in deep ocean sediments. Limnol Oceanogr Methods 7:576-584

Berg P, Long MH, Huettel M, Rheuban JE and others (2013) Eddy correlation measurements of oxygen fluxes in permeable sediments exposed to varying current flow and light. Limnol Oceanogr 58:1329-1343

> Berg P, Reimers CE, Rosman JH, Huettel M, Delgard ML, Reidenbach MA, Özkan-Haller T (2015) Technical note: iime lag correction of aquatic eddy covariance data measured in the presence of waves. Biogeosci Discuss 12:8395-8427

- Blake C, Maggs CA (2003) Comparative growth rates and internal banding periodicity of maerl species (Corralinales, Rhodophyta) from northern Europe. Phycologia 42:606-612

Brand A, McGinnis DF, Wehrli B, Wüest A (2008) Intermittent oxygen flux from the interior into the bottom boundary of lakes as observed by eddy correlation. Limnol Oceanogr 53:1997-2006

> Burdett HL, Kamenos NA, Law A (2011) Using coralline algae to understand historic marine cloud cover. Palaeogeogr Palaeoclimatol Palaeoecol 302:65-70

Cahoon LB (1999) The role of benthic microalgae in neritic ecosystems. Oceanogr Mar Biol Annu Rev 37:47-86

$>$ Davoult D, Gounin F (1995) Suspension-feeding activity of a dense Ophiothrix fragilis (Abildgaard) population at the water-sediment interface: time coupling of food availability and feeding behavior of the species. Estuar Coast Shelf Sci 41:567-577

> Donis D, Holtappels M, Noss C, Cathalot C and others (2015) An assessment of the precision and confidence of aquatic eddy correlation measurements. J Atmos Ocean Technol 32:642-655

> Epping EHG, Jørgensen BB (1996) Light-enhanced oxygen respiration in benthic phototrophic communities. Mar Ecol Prog Ser 139:193-203

Fenchel T, Glud RN (2000) Benthic primary production and $\mathrm{O}_{2}-\mathrm{CO}_{2}$ dynamics in a shallow-water sediment: spatial and temporal heterogeneity. Ophelia 53:159-171 
Foster MS (2001) Rhodoliths: between rocks and soft places. J Phycol 37:659-667

- Gattuso JP, Gentili B, Duarte CM, Kleypas JA, Middelburg JJ, Antoinne D (2006) Light availability in the coastal ocean: impact on the distribution of benthic photosynthetic organisms and their contribution to primary production. Biogeosciences 3:489-513

$>$ Glud RN (2008) Oxygen dynamics of marine sediments. Mar Biol Res 4:243-289

> Glud RN, Blackburn N (2002) The effect of chamber size on benthic oxygen uptake measurements: a simulation study. Ophelia 56:23-31

$>$ Glud RN, Forster S, Huettel M (1996) Influence of radial pressure gradients on solute exchange in stirred benthic chambers. Mar Ecol Prog Ser 141:303-311

Glud RN, Woelfel J, Karsten U, Kuhl M, Rysgaard S (2009) Benthic microalgal production in the Arctic: applied methods and status of the current database. Bot Mar 52: 559-571

Glud RN, Berg P, Hume A, Batty P, Blicher ME, Lennert K, Rysgaard $S$ (2010) Benthic oxygen exchange across hard bottom substrates quantified by eddy correlation in a sub-Arctic fjord. Mar Ecol Prog Ser 417:1-12

Graham A (1988) Molluscs: prosobranch and pyramidellid gastropods. EJ Brill, London

Grall J, Le Loc'h F, Guyonnet B, Riera P (2006) Community structure and food web based on stable isotopes $\left(\delta^{15} \mathrm{~N}\right.$ and $\delta^{13} \mathrm{C}$ ) analysis of a North Eastern Atlantic maerl bed. J Exp Mar Biol Ecol 338:1-15

Gundersen JK, Ramsing NB, Glud RN (1998) Predicting the signal of $\mathrm{O}_{2}$ microsensors from physical dimensions, temperature, salinity, and $\mathrm{O}_{2}$ concentration. Limnol Oceanogr 43:1932-1937

Holtappels M, Glud RN, Donis D, Liu B, Hume A, Wenzhoefer F, Kuypers M (2013) Effect of transient bottom water currents and oxygen concentrations on benthic exchange rates as assessed by eddy correlation measurements. J Geophys Res 118:1157-1169

Holtappels M, Noss C, Hancke K, Cathalot C, McGinnis DF, Lorke A, Glud RN (2015) Aquatic eddy correlation: quantifying the artificial flux caused by stirring-sensitive $\mathrm{O}_{2}$ sensors. PLoS ONE 10:e0116564

Huettel M, Gust G (1992) Impact of bioroughness on interfacial solute exchange in permeable sediments. Mar Ecol Prog Ser 89:253-267

- Huettel M, Røy H, Precht E, Ehrenhauss S (2003) Hydrodynamical impact on biogeochemical processes in aquatic sediments. Hydrobiologia 494:231-236

Huettel M, Berg P, Kostka JE (2014) Benthic exchange and biogeochemical cycling in permeable sediments. Annu Rev Mar Sci 6:23-51

> Hume AC, Berg P, McGlathery KJ (2011) Dissolved oxygen fluxes and ecosystem metabolism in an eelgrass (Zostera marina) meadow measured with the eddy correlation technique. Limnol Oceanogr 56:86-96

> Johnson KS, Barry JP, Coletti LJ, Fitzwater SE, Jannasch HW, Lovera C (2011) Nitrate and oxygen flux across the sediment-water interface observed by eddy correlation measurements on the open continental shelf. Limnol Oceanogr Methods 9:543-553

- Kamenos NA, Moore PG, Hall-Spencer JM (2003) Substratum heterogeneity of dredged vs. un-dredged maerl grounds. J Mar Biol Assoc UK 83:411-413

Kamenos NA, Moore PG, Hall-Spencer JM (2004a) Nurseryarea function of maerl grounds for juvenile queen scal- lops Aequipecten opercularis and other invertebrates. Mar Ecol Prog Ser 274:183-189

Kamenos NA, Moore PG, Hall-Spencer JM (2004b) Smallscale distribution of juvenile gadoids in shallow inshore waters: What role does maerl play? ICES J Mar Sci 61: 422-429

Klute A, Dirksen C (1986) Hydraulic conductivity and diffusivity: laboratory methods. In: Klute A (ed) Methods of soil analysis, Part 1: Physical and mineralogical methods. American Society of Agronomy, Madison, WI, p 687-734

Long MH, Berg P, de Beer D, Zieman JC (2013) In situ coral reef oxygen metabolism: an eddy correlation study. PLoS ONE 8:e58581

Lorke A, McGinnis DF, Maeck A (2013) Eddy-correlation measurements of benthic fluxes under complex flow conditions: effects of coordinate transformations and averaging time scales. Limnol Oceanogr Methods 11:425-437

- Martin S, Clavier J, Guarini JM, Chauvaud L and others (2005) Comparison of Zostera marina and maerl community metabolism. Aquat Bot 83:161-174

Martin S, Clavier J, Chauvaud L, Thouzeau G (2007) Community metabolism in temperate maerl beds. I. Carbon and carbonate fluxes. Mar Ecol Prog Ser 335:19-29

Martin S, Charnoz A, Gattuso JP (2013) Photosynthesis, respiration and calcification in the Mediterranean crustose coralline alga Lithophyllum cabiochae (Corralinales, Rhodophyta). Eur J Phycol 48:163-172

> Martin CS, Giannoulaki M, De Leo F, Scardi M and others (2014) Corraligenous and maerl habitats: predictive modelling to identify their spatial distributions across the Mediterranean Sea. Sci Rep 4:5073

McGinnis DF, Berg P, Brand A, Lorrai C, Edmonds TJ, Wüest A (2008) Measurements of eddy correlation oxygen fluxes in shallow freshwaters: towards routine applications and analysis. Geophys Res Lett 35:LD4403, doi: 10.1029/2007GL032747

> McGinnis DF, Cherednichenko S, Sommer S, Berg P and others (2011) Simple, robust eddy correlation amplifier for aquatic dissolved oxygen and hydrogen sulfide flux measurements. Limnol Oceanogr Methods 9:340-347

> McGinnis DF, Sommer S, Lorke A, Glud RN, Linke P (2014) Quantifying tidally-driven benthic oxygen exchange across permeable sediments: an aquatic eddy correlation study. J Geophys Res 119:6918-6932

McPhee M (2008) Air-ice-ocean interaction: turbulent ocean boundary layer exchange processes. Springer, New York, NY

Middelburg JJ, Duarte CM, Gattuso JP (2005) Respiration in coastal benthic communities. In: Del Giorgio PA, Williams PJLB (eds) Respiration in aquatic ecosystems. Oxford University Press, Oxford, p 206-225

Mori N, Suzuki T, Kakuno S (2007) Noise of acoustic Doppler velocimeter data in bubbly flow. J Eng Mech 133:122-125

> Rees AP, Owens NJP, Heath MR, Plummer DH, Bellerby RS (1995) Seasonal nitrogen assimilation and carbon fixation in a fjordic sea loch. J Plankton Res 17:1307-1324

Reimers CE, Özkan-Haller HT, Berg P, Devol A, McCannGrosvenor K, Sanders RD (2012) Benthic oxygen consumption rates during hypoxic conditions on the Oregon continental shelf: evaluation of the eddy correlation method. J Geophys Res 117:C02021, doi:10.1029/ 2011JC007564

Revsbech NP (1989) An oxygen microelectrode with a guard cathode. Limnol Oceanogr 34:474-478 
Rheuban JE, Berg P (2013) The effects of spatial and temporal variability at the sediment surface on aquatic eddy correlation flux measurements. Limnol Oceanogr Methods 11:351-359

Rheuban JE, Berg P, McGlathery KJ (2014) Multiple timescale processes drive ecosystem metabolism in eelgrass (Zostera marina) meadows. Mar Ecol Prog Ser 507:1-13

Roberts RD, Kühl M, Glud RN, Rysgaard S (2002) Primary production of crustose coralline red algae in a high Arctic fjord. J Phycol 38:273-283

Rovelli L, Attard KM, Bryant LD, Flögel S and others (2015)

Editorial responsibility: Ronald Kiene,

Mobile, Alabama, USA
Benthic $\mathrm{O}_{2}$ uptake of two cold-water coral communities estimated with the non-invasive eddy correlation technique. Mar Ecol Prog Ser 525:97-104

Teichert S (2014) Hollow rhodoliths increase Svalbard's shelf biodiversity. Nat Sci Rep 4:6972

Wenzhöfer F, Glud RN (2004) Small-scale spatial and temporal variability in coastal benthic $\mathrm{O}_{2}$ dynamics: effects of fauna activity. Limnol Oceanogr 49:1471-1481

Wiberg PL, Smith JD (1987) Calculations of the critical shear-stress for motion of uniform and heterogeneous sediments. Water Resour Res 23:1471-1480

Submitted: April 14, 2015; Accepted: July 7, 2015

Proofs received from author(s): August 25, 2015 